\title{
Optimization of Magnetic Properties of Magnetic Microwires by Post-Processing
}

\author{
Valentina Zhukova 1,2 (D), Paula Corte-Leon 1,2 ${ }^{(D)}$, Lorena González-Legarreta 1,3, \\ Ahmed Talaat ${ }^{1,4} \mathbb{D}$, Juan Maria Blanco ${ }^{2}$, Mihail Ipatov ${ }^{1}$, Jesus Olivera ${ }^{5,6}(\mathbb{D}$ and \\ Arcady Zhukov 1,2,7,*(1)
}

1 Department. Material Physics, Faculty of Chemistry, University of Basque Country, UPV/EHU, 20018 San Sebastian, Spain; valentina.zhukova@ehu.es (V.Z.); paula.corte@ehu.eus (P.C.-L.); lorena.glegarreta@gmail.com (L.G.-L.); aht17@pitt.edu (A.T.); mihail.ipatov@ehu.es (M.I.)

2 Department Applied Physics I, Escuela de Ingeniería de Gipuzkoa, EIG, University of Basque Country, UPV/EHU, 20018 San Sebastian, Spain; juanmaria.blanco@ehu.es

3 Department. QUIPRE, Inorganic Chemistry-University of Cantabria, Nanomedice-IDIVAL, Avda. de Los Castros 46, 39005 Santander, Spain

4 Department of Mechanical Engineering \& Materials Science, Swanson School of Engineering, University of Pittsburgh, Pittsburgh, PA 15261, USA

5 Pontificia Universidad Católica Madre y Maestra, PUCMM, Autopista Duarte, Km 1 1⁄2, Santiago de los Caballeros 51000, Dominican Republic; j.olivera@aduanas.gob.do

6 Laboratorio de la Dirección General de Aduanas, Carlos Sánchez, Esquina Lope de Vega, Ensanche Naco, Santo Domingo 10119, Dominican Republic

7 IKERBASQUE, Basque Foundation for Science, 48011 Bilbao, Spain

* Correspondence: arkadi.joukov@ehu.es; Tel.: +34-943-01-8611

Received: 13 July 2020; Accepted: 10 August 2020; Published: 18 August 2020

\begin{abstract}
The influence of post-processing conditions on the magnetic properties of amorphous and nanocrystalline microwires has been thoroughly analyzed, paying attention to the influence of magnetoelastic, induced and magnetocrystalline anisotropies on the hysteresis loops of $\mathrm{Fe}-$, $\mathrm{Ni}$-, and Co-rich microwires. We showed that magnetic properties of glass-coated microwires can be tuned by the selection of appropriate chemical composition and geometry in as-prepared state or further considerably modified by appropriate post-processing, which consists of either annealing or glass-coated removal. Furthermore, stress-annealing or Joule heating can further effectively modify the magnetic properties of amorphous magnetic microwires owing to induced magnetic anisotropy. Devitrification of microwires can be useful for either magnetic softening or magnetic hardening of the microwires. Depending on the chemical composition of the metallic nucleus and on structural features (grain size, precipitating phases), nanocrystalline microwires can exhibit either soft magnetic properties or semi-hard magnetic properties. We demonstrated that the microwires with coercivities from $1 \mathrm{~A} / \mathrm{m}$ to $40 \mathrm{kA} / \mathrm{m}$ can be prepared.
\end{abstract}

Keywords: magnetic microwires; post-processing; hysteresis loops; magnetic anisotropy

\section{Introduction}

The development of new magnetic devices (sensors, actuators, magnetometers, transformers, motors, etc.) is substantially affected by technological progress in the field of magnetic materials [1-3]. The performance of the magnetic devices is determined by their properties: the right choice of magnetic material allows for devices' performance improvement. Soft magnetic materials are essentially relevant for a number of emerging applications [3]. 
Amorphous and nanocrystalline materials prepared by means of rapid melt quenching present unique combination of physical properties, such as superior magnetic softness, dimensionality suitable for various industrial applications, and excellent mechanical properties [4-6]. Given that the fabrication process of amorphous and nanocrystalline materials is usually fast and inexpensive, these materials are recognized among the most promising soft magnetic materials. Several fabrication techniques involving rapid melt quenching allow preparation of amorphous materials with either cylindrical (wires) or planar (ribbons) geometries [4-6]. Accordingly, amorphous ribbons and wires can present rather different magnetic properties and, hence, they are suitable for a wide range of applications. In particular, for energy and power conversion applications in transformers, amorphous and nanocrystalline with low magnetic losses and high values of saturation magnetization are more suitable [4]. In contrast, amorphous, nanocrystalline, and even crystalline wires can exhibit rather unique magnetic properties, such as the giant magneto-impedance effect (GMI) or fast magnetization switching associated with a perfectly rectangular hysteresis loop shape and attributed to a large Barkhausen jump [7-15].

It is worth mentioning that a considerable GMI effect has been observed also in amorphous and nanocrystalline ribbons $[16,17]$. However, the specific domain structure of magnetic wires consisting of inner axially magnetized domain surrounded by the outer domain shell allows for achieving high circumferential magnetic permeability in Co-rich amorphous wires or large Barkhausen jump upon remagnetization of axially magnetized single domain in Fe-rich amorphous wires [18-20]. The origin of such domain structure is dictated by the internal stresses distribution originated by the rapid melt quenching fabrication process. Accordingly, both high GMI effect and fast magnetization switching related to propagation of a single domain wall, DW, can be observed even in as-prepared amorphous magnetic wires [18-20]. Recently, fast DW propagation has been reported also in nanowires prepared either by electrodeposition [21,22] or involving a rapid melt quenching technique [20,23,24].

As mentioned above, most of the studies are related (although not limited) to either single DW dynamics or GMI effect. The main interest in the GMI effect is related to extremely large impedance sensitivity to an external magnetic field (up to $10 \% / \mathrm{A} / \mathrm{m}$ ) observed in properly prepared and processed magnetic microwires $[10-13,18,25,26]$. Such features of the GMI effect observed in amorphous wires allowed the development of the GMI technology suitable for numerous applications, such as magnetic compass and acceleration sensors integrated in complementary metal-oxide-semiconductor (CMOS) circuits [27,28], reduced-sized magnetometer suitable for magnetic field mapping [29,30], detection of a biomagnetic field with the pico-Tesla sensitivity [31], and magnetoelastic and temperature sensors [32,33].

A variety of technological applications require miniaturization combined with excellent corrosion and mechanical properties and biocompatibility of the magnetic elements [2-4,12-14]. This combination of physical properties and reduced dimensions can be achieved in glass-coated microwires: among the rapid melt quenching methods, the so-called Taylor-Ulitovsky method allows preparation of the thinnest amorphous wires covered by flexible and insulating glass [34-37]. It is worth mentioning that the method itself has been known since the 1960s [34], and the preparation of magnetic amorphous microwires has been reported about since the 1970s [18,35,36]. The preparation method consists of the fabrication of glass-coated microwires with metallic nucleus, diameters typically from submicrometric up to $40 \mu \mathrm{m}$, by simultaneous rapid melt quenching of metallic alloy covered by insulating glass coating [36]. This method is suitable for fabrication of magnetic microwires with either amorphous or nano-micro crystalline structure [18,23-25,33,36-38].

A variety of magnetic properties interesting for various technological applications, such as a high GMI effect (up to $650 \%$ GMI ratio) [18,25,26], extremely fast single domain wall (DW) propagation (with DW velocity up to $3 \mathrm{~km} / \mathrm{s}$ ) [19,23,24,38], considerable magnetoresistance [36,39], and magnetocaloric $[36,40]$ effects or even semi-hard magnetic properties $[36,41]$ have been reported for glass-coated microwires.

As discussed elsewhere [36], the magnetic properties of microwires to a great extent are determined by the microstructure of the metal core. The microstructure depends on fabrication 
conditions, like the quenching rate as well as the chemical composition of the metallic nucleus alloy. Thus, if the quenching rate achieved during the quenching process from the melt is not high enough, metastable crystalline microwires with crystalline structure of metallic alloy nucleus can be prepared $[36,40,41]$. However, even magnetic properties of amorphous microwires are affected by the fabrication conditions (like quenching rate or glass-coating thickness) and chemical composition of the metallic alloy [18,42-44]. This compositional dependence is related to the magnetoelastic anisotropy affected by the magnetostriction coefficient as well as by the internal stresses values [18,43-47]. However, appropriate post- processing is another factor allowing for either fine-tuning or even drastic modification of magnetic properties [43,44,48].

In this review, we have analyzed the influence of various factors on the magnetic properties of glass-coated microwires and provide the guideline for selection of appropriate post-processing for optimization of properties of magnetic microwires.

\section{Experimental Methods and Materials}

We prepared and analyzed amorphous glass-coated microwires based on $\mathrm{Fe}-, \mathrm{Co}-$ and $\mathrm{Ni}$ - alloys with minor metalloid additions ( $\mathrm{Si}, \mathrm{B}, \mathrm{C})$ necessary for preparation of amorphous alloys $[6-8,12,36]$ (Table 1). The employed Taylor-Ulitovsky technique is described earlier elsewhere [36].

Table 1. Compositions and geometry of studied glass-coated microwires.

\begin{tabular}{|c|c|c|c|c|}
\hline Composition & $\begin{array}{c}\text { Metallic Nucleus } \\
\text { Diameter, } \\
\text { d }(\mu \mathrm{m})\end{array}$ & $\begin{array}{l}\text { Total Diameter, } \\
\text { D }(\mu \mathrm{m})\end{array}$ & Ratio $=\mathrm{d} / \mathrm{D}$ & $\begin{array}{c}\text { Magnetostriction } \\
\text { Coefficient, } \\
\lambda_{\mathrm{s}} \times 10^{-6}\end{array}$ \\
\hline $\mathrm{Fe}_{62} \mathrm{Ni}_{15.5} \mathrm{Si}_{7.5} \mathrm{~B}_{15}$ & 14.35 & 33.25 & 0.43 & 27 \\
\hline $\mathrm{Fe}_{49.6} \mathrm{Ni}_{27.9} \mathrm{Si}_{7.5} \mathrm{~B}_{15}$ & 14.2 & 33.85 & 0.42 & 20 \\
\hline $\mathrm{Co}_{70.5} \mathrm{Mn}_{4.5} \mathrm{Si}_{10} \mathrm{~B}_{15}$ & 10 & 26 & 0.38 & -0.2 \\
\hline $\mathrm{Co}_{77.5} \mathrm{Si}_{15} \mathrm{~B}_{7.5}$ & 13.1 & 18 & 0.73 & -5 \\
\hline $\mathrm{Co}_{69.2} \mathrm{Fe}_{3.6} \mathrm{Ni}_{1} \mathrm{~B}_{12.5} \mathrm{Si}_{11} \mathrm{C}_{1.2} \mathrm{Mo}_{1.5}$ & 22.8 & 23.2 & 0.98 & -1 \\
\hline $\mathrm{Co}_{68.5} \mathrm{Si}_{14.5} \mathrm{~B}_{14.5} \mathrm{Y}_{2.5}$ & 5 & 22 & 0.23 & -5 \\
\hline $\mathrm{Co}_{65.4} \mathrm{Fe}_{3.8} \mathrm{Ni}_{1} \mathrm{~B}_{13.8} \mathrm{Si}_{13} \mathrm{C}_{1.65} \mathrm{Mo}_{1.35}$ & 18.8 & 22.2 & 0.85 & -1 \\
\hline $\mathrm{Co}_{67} \mathrm{Fe}_{3.85} \mathrm{Ni}_{1.45} \mathrm{~B}_{11.5} \mathrm{Si}_{14.5} \mathrm{Mo}_{1.7}$ & 6.6 & 15.7 & 0.42 & -3 \\
\hline $\mathrm{Co}_{67} \mathrm{Fe}_{3.85} \mathrm{Ni}_{1.45} \mathrm{~B}_{11.5} \mathrm{Si}_{14.5} \mathrm{Mo}_{1.7}$ & 6.8 & 13.6 & 0.5 & -3 \\
\hline $\mathrm{Co}_{67} \mathrm{Fe}_{3.85} \mathrm{Ni}_{1.45} \mathrm{~B}_{11.5} \mathrm{Si}_{14.5} \mathrm{Mo}_{1.7}$ & 9.8 & 18.5 & 0.53 & -3 \\
\hline $\mathrm{Co}_{67} \mathrm{Fe}_{3.85} \mathrm{Ni}_{1.45} \mathrm{~B}_{11.5} \mathrm{Si}_{14.5} \mathrm{Mo}_{1.7}$ & 11.8 & 18.4 & 0.64 & -3 \\
\hline $\mathrm{Co}_{67} \mathrm{Fe}_{3.85} \mathrm{Ni}_{1.45} \mathrm{~B}_{11.5} \mathrm{Si}_{14.5} \mathrm{Mo}_{1.7}$ & 13.4 & 20.9 & 0.64 & -3 \\
\hline $\mathrm{Co}_{67} \mathrm{Fe}_{3.85} \mathrm{Ni}_{1.45} \mathrm{~B}_{11.5} \mathrm{Si}_{14.5} \mathrm{Mo}_{1.7}$ & 16.8 & 24 & 0.7 & -3 \\
\hline $\mathrm{Co}_{67} \mathrm{Fe}_{3.85} \mathrm{Ni}_{1.45} \mathrm{~B}_{11.5} \mathrm{Si}_{14.5} \mathrm{Mo}_{1.7}$ & 16.8 & 21 & 0.8 & -3 \\
\hline $\mathrm{Co}_{69.2} \mathrm{Fe}_{4.1} \mathrm{~B}_{11.8} \mathrm{Si}_{13.8} \mathrm{C}_{1.1}$ & 25.6 & 30.2 & 0.85 & -0.03 \\
\hline $\mathrm{Fe}_{71,8} \mathrm{Cu}_{1} \mathrm{Nb}_{3,1} \mathrm{Si}_{15} \mathrm{~B}_{9,1}$ & 7.0 & 24.8 & 0.282 & 30 \\
\hline $\mathrm{Fe}_{71,8} \mathrm{Cu}_{1} \mathrm{Nb}_{3,1} \mathrm{Si}_{15} \mathrm{~B}_{9,1}$ & 18.2 & 39 & 0.467 & 30 \\
\hline $\mathrm{Fe}_{70.8} \mathrm{Cu}_{1} \mathrm{Nb}_{3.1} \mathrm{Si}_{14.5} \mathrm{~B}_{10.6}$ & 11.8 & 14.4 & 0.8 & 30 \\
\hline $\mathrm{Co}_{67} \mathrm{Fe}_{3.9} \mathrm{Ni}_{1.5} \mathrm{~B}_{11.5} \mathrm{Si}_{14.5} \mathrm{Mo}_{1.6}$ & 25.6 & 26.6 & 0.96 & -0.29 \\
\hline $\mathrm{Co}_{68.7} \mathrm{Fe}_{4} \mathrm{Ni}_{1} \mathrm{~B}_{13} \mathrm{Si}_{11} \mathrm{Mo}_{2.3}$ & 17 & 23.6 & 0.72 & -1.06 \\
\hline $\mathrm{Fe}_{38.5} \mathrm{Co}_{38.5} \mathrm{~B}_{18} \mathrm{Mo}_{4} \mathrm{Cu}_{1}$ & 9.4 & 22.5 & 0.41 & \\
\hline $\mathrm{Fe}_{38.5} \mathrm{Co}_{38.5} \mathrm{~B}_{18} \mathrm{Mo}_{4} \mathrm{Cu}_{1}$ & 10 & 16.6 & 0.6 & \\
\hline $\mathrm{Fe}_{50} \mathrm{Pt}_{40} \mathrm{Si}_{10}$ & 8 & 21 & 0.38 & \\
\hline
\end{tabular}

The structure of the samples has been analyzed by the X-ray Diffraction (XRD) as well as by the Differential Scanning Calorimeter (DSC). The Bruker (D8 Advance) X-ray diffractometer with Cu $\mathrm{K}_{\alpha}$ $(\lambda=1.54 \AA)$ radiation has been used in the XRD studies. A wide halo characteristic of completely amorphous materials was observed in amorphous (as-prepared or annealed) microwires. The DSC studies were performed using a 204 F1 Netzsch calorimeter (Netzsch Co, Selb, Germany).

The samples were heat treated at a temperature, $T_{\text {ann }}$, ranging from $200{ }^{\circ} \mathrm{C}$ to $500{ }^{\circ} \mathrm{C}$ in a conventional furnace. Typically, the crystallization of amorphous microwires was reported for $T_{a n n} \geq 490^{\circ} \mathrm{C}$ [49]. The advantage of amorphous microwires is their superior mechanical properties 
typically reported for amorphous materials [50,51]. In most cases, we fixed annealing time, $t_{\text {ann }}$, of $60 \mathrm{~min}$ which is usually used for heat treatment of amorphous and nanocrystalline materials $[48,49]$.

In the case of stress-annealing, the tensile stress was applied during the annealing, as well as during the sample cooling in the furnace. The stress value in the metallic nucleus, $\sigma_{m}$, was evaluated considering different Young's modulus of metal, $E_{2}$, and glass, $E_{1}$, as follows $[43,48,52]$ :

$$
\sigma_{m}=\frac{K \cdot P}{K \cdot S_{m}+S_{g l}}
$$

where $K=E_{2} / E_{1}, S_{m}$, and $S_{g l}$ are the metallic nucleus and the glass coating cross sections, respectively, and $P$ is the applied mechanical load.

Hysteresis loops have been recorded using the fluxmetric method adapted for studies of magnetic microwires [49]. Hysteresis loops have been represented as the normalized magnetization, $M / M_{0}$, versus the axial magnetic field, $H$, where $M_{o}$ is the sample magnetic moment obtained at the maximum magnetic field amplitude, $H_{0}[49,53]$.

The magnetostriction coefficient, $\lambda_{s}$, of the studied microwire, was evaluated by the Small Angle Magnetization Rotation (SAMR) method recently adapted for microwire [54,55]. In this method, $\lambda_{S}$-values are determined in the microwire saturated by an axial magnetic field, $H$. Simultaneously, a low AC transverse field, $H_{c}$, generated by an AC electric current flowing along the microwire allows a reversible magnetization rotation. A more detailed SAMR method description and of the set-up adapted for evaluation of magnetostriction coefficient in microwires are provided elsewhere $[54,55]$.

The glass coating was removed from the microwires by chemical etching using diluted $(10 \%)$ hydrofluoric (HF) acid.

\section{Results and Discussion}

Below, we have summarized the highlight findings already published, together with recently obtained results on tailoring of magnetic properties of glass-coated microwires, with particular emphasis placed on amorphous and crystalline microwires.

\subsection{Effect of Magnetoelastic Anisotropy on Magnetic Properties of Amorphous Glass-Coated Microwires}

The sign and value of the magnetostriction coefficient affect the hysteresis loops of amorphous microwires, since magnetoelastic anisotropy is the main source of magnetic anisotropy in amorphous materials. Accordingly, the simplest way to tune the magnetostriction coefficient, $\lambda_{s}$, in amorphous alloys is to modify its chemical composition [54-57].

Fe-rich microwires have positive $\lambda_{s}$-values, of the order $\lambda_{s} \sim(20-40) \times \cdot 10^{-6}$, while in Co-rich microwires $\lambda_{s}$ are negative, taking $\lambda_{s} \sim-(5-3) \times 10^{-6}$ [56,57]. Accordingly, the magnetostriction can take vanishing values in Co-Fe or Co-Mn amorphous alloys on the Co-rich side [54-58]. Alternatively, a decrease in $\lambda_{s}$ is observed in Fe-Ni alloys with an increase in Ni content. However, doping with $\mathrm{Ni}$ correlates with a simultaneous decrease in saturation magnetization [57].

The relationship between the $\lambda_{s}$ sign and value and the hysteresis loops of amorphous microwires is shown in Figure 1. As can be appreciated from Figure 1, the character of hysteresis loops for amorphous microwires with positive and negative $\lambda_{s}$-values is rather different: amorphous microwires with positive $\lambda_{s}$-values present rectangular hysteresis loops, while hysteresis loops of microwires with negative $\lambda_{s}$-values are almost non-hysteretic with low coercitivity, $H_{c}$, values. 


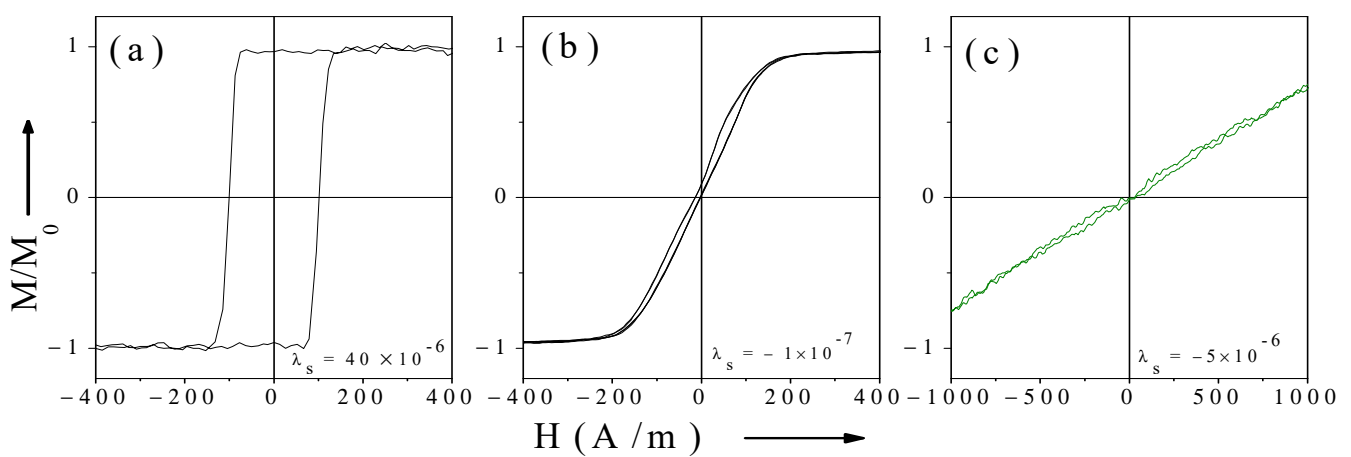

Figure 1. Hysteresis loops of magnetic microwires $\mathrm{Fe}_{75} \mathrm{~B}_{9} \mathrm{Si}_{12} \mathrm{C}_{4}$ with positive (a) $\mathrm{Co}_{67.1} \mathrm{Fe}_{3.8} \mathrm{Ni}_{1.4} \mathrm{Si}_{14.5} \mathrm{~B}_{11.5} \mathrm{Mo}_{1.7}$ with vanishing (b) and $\mathrm{Co}_{77.5} \mathrm{Si}_{15} \mathrm{~B}_{7.5}$ with negative (c) $\lambda_{s}$ values. (Reproduced with permission from [42] Open Access Copyright (C) 2019 MDPI).

Such difference in hysteresis loops character is commonly attributed to different magnetic anisotropy of microwires with positive and negative $\lambda_{S}$-values: the rectangular hysteresis loop of microwires with positive $\lambda_{s}$-values was interpreted in terms of axial magnetic anisotropy [42]. Thus, axial magnetic anisotropy is intrinsically related to a peculiar domain structure consisting of inner axially magnetized single domain responsible for the remagnetization process by single domain wall propagation and outer domain shell with radial magnetization orientation $[9,59,60]$. The remagnetization of such microwires is running by the single and large Barkhausen jump [9,52,59-61]. Perfectly rectangular hysteresis loop character is related to an extremely fast magnetization switching by single domain wall propagation.

On the other hand, the origin of quasi-linear hysteresis loops (see Figure $1 b, c)$ is related to the quasi-reversible magnetization rotation from the circular to the axial direction upon application of an axial magnetic field [60].

As regarding the aforementioned magnetoelastic anisotropy, $K_{m e}$, another relevant parameter is the internal stresses value, $\sigma_{i}$. Indeed, $K_{m e}$ is given by $[23,38,62-64]$ :

$$
K_{m e}=3 / 2 \lambda_{s} \sigma_{i}
$$

where total stresses, $\sigma=\sigma_{i}+\sigma_{a p p}, \sigma_{a p p}$-applied stresses.

There are several factors responsible for the internal stresses value and distribution: (i) the difference in the thermal expansion coefficients of metallic alloy nucleus solidifying simultaneously with the glass coating surrounding it; (ii) the quenching stresses itself related to the rapid solidification of the metallic alloy nucleus from the surface inside the wire axis; and (iii) the drawing stresses [43-46,62-64].

Most theoretical evaluations of the internal stresses value and distribution show that the largest internal stresses are associated with the difference in the thermal expansion coefficients of the metallic alloy and the glass coating [62-64]. The quenching stresses are roughly an order of magnitude lower [42,43].

There are only several attempts of evaluation of internal stresses associated with the continuous mechanical drawing $[63,64]$. The value of such stresses has been estimated from the results on remanent magnetization measurements in glass-coated microwires with partially removed (by chemical etching) glass-coating under applied tensile stresses $[63,64]$. The value of this stress component depends on the microwire geometry and was estimated to be about 250-600 MPa, i.e., again about an order of magnitude below the internal stresses related to the difference in the thermal expansion coefficients of metallic alloy and the glass coating $[63,64]$. Furthermore, they further enhance the axial internal stresses arising from the difference in the thermal expansion coefficients of the metallic alloy and the glass coating.

Provided description allows for predicting that the internal stresses value inside the metallic nucleus can be tuned by the $\rho$-ratio between the metallic nucleus diameter, $d$, and the total microwire 
diameter, $D(\rho=d / D)[42,43,62-64]$. In fact, this prediction is confirmed experimentally by correlation of magnetic properties, such as coercivity, $H_{c}$, or magnetic anisotropy field, $H_{k}$, in magnetic microwires of various chemical compositions, and $\rho$-ratio [38,42,43,62-64]. Below, we provide several experimental evidence of such correlations.

The influence of controllable glass-coating removal by etching in 10\% HF on hysteresis loops of $\mathrm{Co}_{70.5} \mathrm{Mn}_{4.5} \mathrm{Si}_{10} \mathrm{~B}_{15}$ microwire is shown in Figure 2. Gradual transformation of hysteresis loops from linear to almost perfectly rectangular must be attributed to relaxation of the internal stresses related to the presence of glass-coating. This evolution of hysteresis loops can be understood considering the low negative $\lambda_{s}$-values and the axial character of internal stresses in most of the metallic nucleus [65]. Evident difference in hysteresis loops of as-prepared $\mathrm{Co}_{70.5} \mathrm{Mn}_{4.5} \mathrm{Si}_{10} \mathrm{~B}_{15}$ microwires and microwires of the same composition with partially removed glass-coating experimentally confirms the aforementioned theoretical results on character of internal stresses. Low negative magnetostriction coefficient and preferentially axial character of internal stresses explain linear almost non-hysteretic character of hysteresis loops of as-prepared $\mathrm{Co}_{70.5} \mathrm{Mn}_{4.5} \mathrm{Si}_{10} \mathrm{~B}_{15}$ microwires.

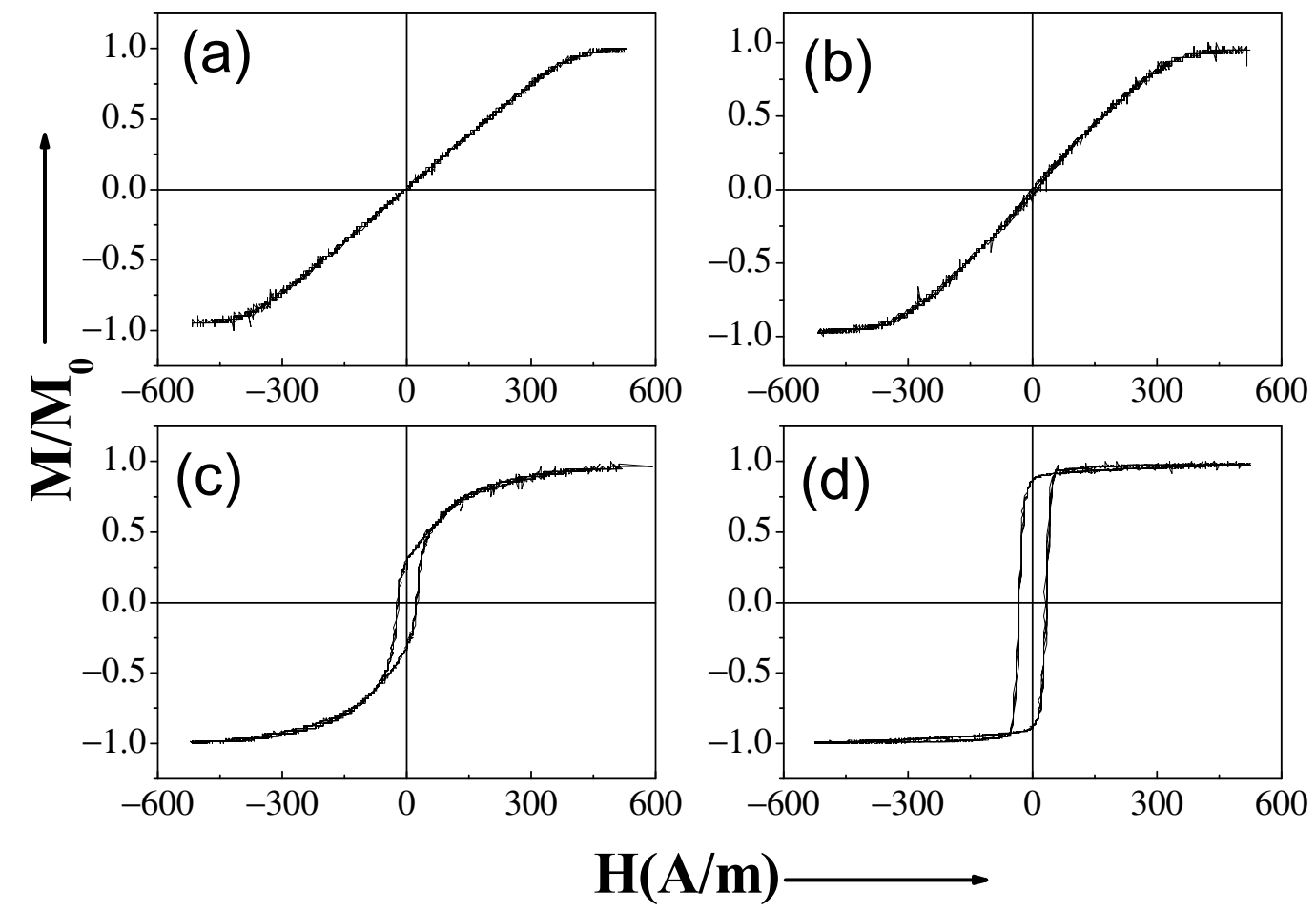

Figure 2. Hysteresis loops of as-prepared (a) and with chemically etched glass-coating for $5 \mathrm{~min}$ (b), $10 \mathrm{~min}$ (c) and $50 \mathrm{~min}$ (d) $\mathrm{Co}_{70.5} \mathrm{Mn}_{4.5} \mathrm{Si}_{10} \mathrm{~B}_{15}$ microwire. (Reproduced with permission from [65], Copyright (C) 2020 Elsevier).

The influence of chemical etching on the hysteresis loops of $\mathrm{Co}_{68.5} \mathrm{Si}_{14.5} \mathrm{~B}_{14.5} \mathrm{Y}_{2.5}$ microwire with higher negative $\lambda_{s}$-values is even more remarkable (see Figure 3): as-prepared $\operatorname{Co}_{68.5} \operatorname{Si}_{14.5} \mathrm{~B}_{14.5} \mathrm{Y}_{2.5}$ microwire presents non-hysteretic loops with saturation at magnetic field, $H$, above $6 \mathrm{kA} / \mathrm{m}$ (see Figure 3a). However, upon chemical etching, gradual transformation of hysteresis loops from linear to rectangular is observed (see Figure 3b,c). As previously reported [66], after etching in 10\% $\mathrm{HF}$ for $50 \mathrm{~min}$, the glass-coating thickness decreases from 8.5 to $4 \mu \mathrm{m}$. Accordingly, the glass-coating thickness can be considered as one of the most relevant parameters that affect the hysteresis loops of glass-coated microwires. 


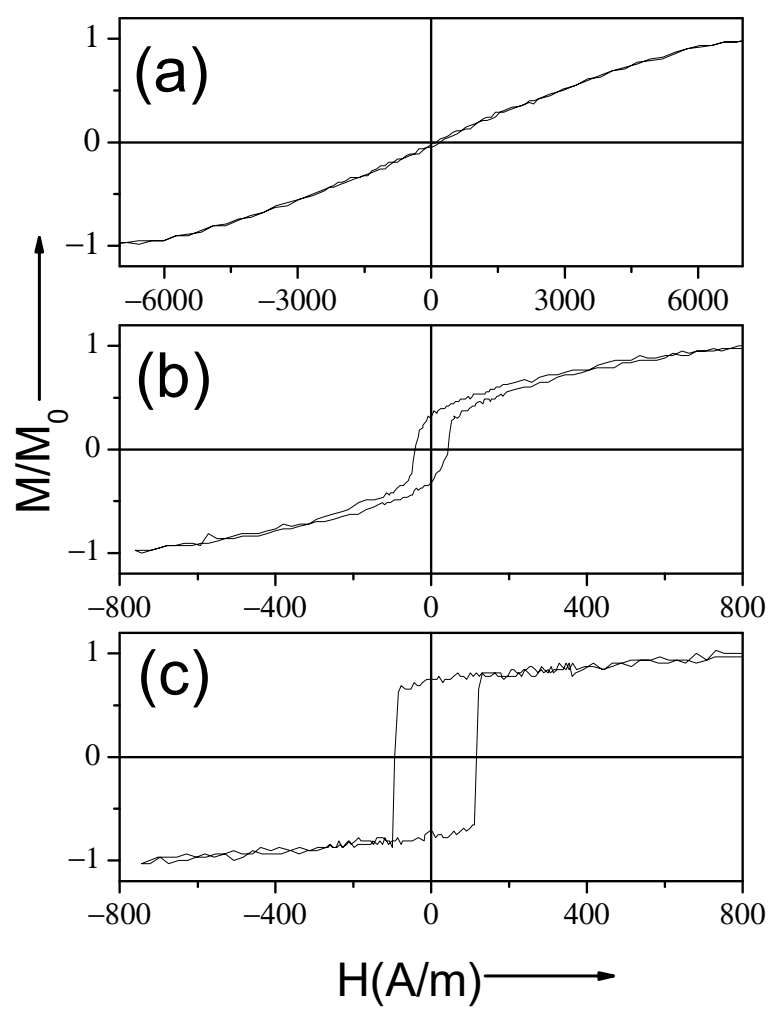

Figure 3. Hysteresis loops of as-prepared (a), and subjected to chemical etching for $35 \mathrm{~min}(\mathbf{b})$ and $50 \min (\mathbf{c}) \mathrm{Co}_{68.5} \mathrm{Si}_{14.5} \mathrm{~B}_{14.5} \mathrm{Y}_{2.5}$ microwires, adapted from [66].

Gradual glass-coating removal by chemical etching must be associated with the gradual relaxation of the internal stresses related to different thermal expansion coefficients of glass coating and metallic alloy.

The commonly accepted model of domain structure of magnetic wires is the core-shell model experimentally proved several times by various methods $[60,61,67,68]$. According to this model, the domain structure of amorphous magnetic wires can be satisfactory described as consisting of inner axially magnetized core surrounded with the outer shell with transverse magnetization. In the case of Fe-rich wires, the outer shell presents radial magnetization orientation, while, in Co-rich microwires, a bamboo-like domain structure with circular magnetization orientation is reported [60,61,67-70].

The origin for such domain structure is discussed considering the minimization of the energy though the counterbalance of the magnetoelastic energy related to the internal stresses distribution as well as to the exchange energy $[69,70]$.

In the frame of this domain structure model, the radius of the inner axially magnetized core, $R_{c}$, can be evaluated from the squareness ratio, $M_{r} / M_{0}$, as:

$$
R_{c}=R \cdot\left(M_{r} / M_{0}\right)^{1 / 2}
$$

where $R$ is the metallic nucleus radius.

From the evolution of the hysteresis loops upon chemical etching provided in Figures 2 and 3, the increase in the $M_{r} / M_{o}$ upon chemical etching is evidenced. Consequently, we can assume that the radius of inner axially magnetized domain increase upon partial internal stresses relaxation associated with the glass removal. This assumption is evidenced from Figure 4 where evolution of $R_{c} / R$ on time of chemical etching, $t$, for $\mathrm{Co}_{70.5} \mathrm{Mn}_{4.5} \mathrm{Si}_{10} \mathrm{~B}_{15}$ and $\mathrm{Co}_{68.5} \mathrm{Si}_{14.5} \mathrm{~B}_{14.5} \mathrm{Y}_{2.5}$ microwires is shown. As can be observed, for the microwire with lower $\lambda_{s}$-value, the increase in $R_{c} / R$ with $t$ is faster. 


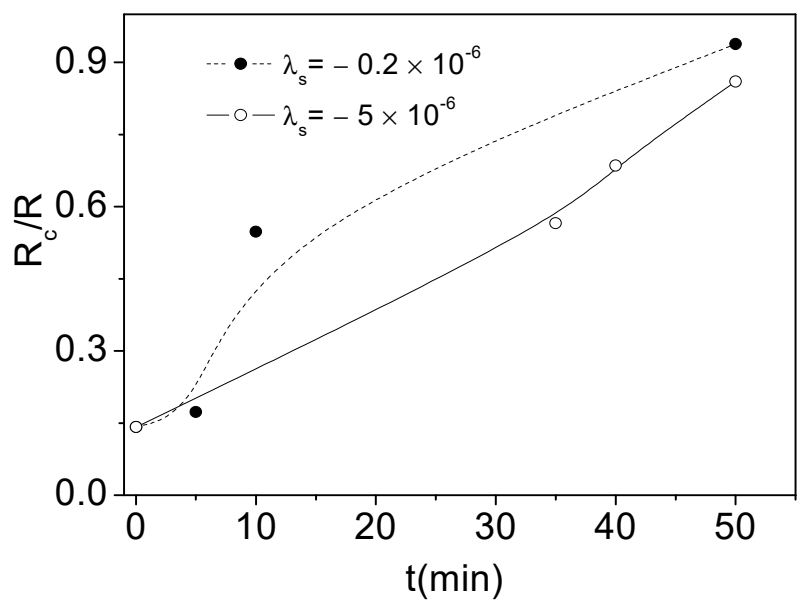

Figure 4. $R c / R(t)$ dependencies for $\mathrm{Co}_{70.5} \mathrm{Mn}_{4.5} \mathrm{Si}_{10} \mathrm{~B}_{15}$ and $\mathrm{Co}_{68.5} \mathrm{Si}_{14.5} \mathrm{~B}_{14.5} \mathrm{Y}_{2.5}$ microwires. The lines are just guides for eyes.

In order to prove the axial character of the internal stresses related to glass-coating (i.e., to the difference in thermal expansion coefficients of glass and metallic alloy), we evaluated the influence of applied tensile stresses, $\sigma$, on the hysteresis loops of Co-rich $\left(\mathrm{Fe}_{3.8} \mathrm{Co}_{65.4} \mathrm{Ni}_{1} \mathrm{~B}_{13.8} \mathrm{Si}_{13} \mathrm{Mo}_{1.35} \mathrm{C}_{1.65}\right)$ microwires with a linear hysteresis loop.

As shown in Figure $5 \mathrm{a}$, when tensile stress, $\sigma_{\text {app }}$, is applied, magnetic anisotropy field, $H_{k}$, increases. At the same time, the hysteresis loops character (linear hysteresis loop with low coercivity) of the studied microwire remains almost the same.
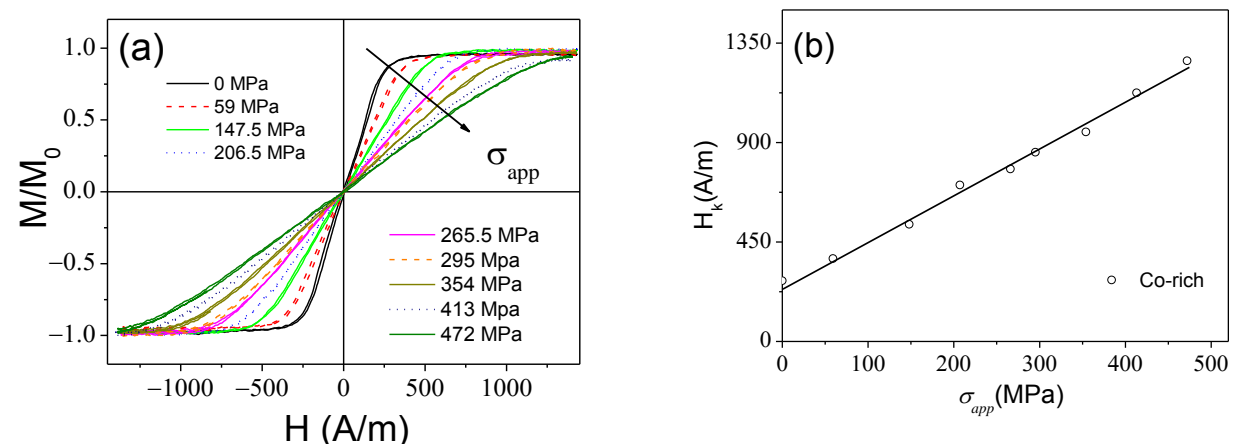

Figure 5. Effect of applied stress on hysteresis loops (a) and $H_{k}\left(\sigma_{\text {app }}\right)$ (b) for as-prepared $\mathrm{Fe}_{3.8} \mathrm{Co}_{65.4} \mathrm{Ni}_{1} \mathrm{~B}_{13.8} \mathrm{Si}_{13} \mathrm{Mo}_{1.35} \mathrm{C}_{1.65}$ microwires. (Reproduced with permission from [71] Figures 2 and $3 \mathrm{a}$ Copyright (C) 2019 Elsevier B.V.)

$H_{k}\left(\sigma_{\text {app }}\right)$ dependence evaluated from Figure 5a shows a good linear tendency (Figure $5 \mathrm{~b}$ ). Such linear $H_{k}\left(\sigma_{a p p}\right)$ dependence has been explained considering the relationship between the magnetoelastic anisotropy, $K_{m e}$, and $\sigma_{\text {app }}$ given by Equation (2) [71]. Consequently, relation between the magnetostriction coefficient and magnetic anisotropy field, $H_{k}$, is given by [71]:

$$
\lambda_{s}=\mu_{0} M_{s}\left(H_{k} / 3 \sigma\right)
$$

where $\mu_{0} M_{s}$ is the saturation magnetization.

The magnetostriction coefficient is affected by the stresses, $\sigma$, as described elsewhere [71,72]:

$$
\lambda_{s, \sigma}=\lambda_{s, 0}-B \sigma
$$

where $\lambda_{s, \sigma}$ is the magnetostriction coefficient under stress, $\lambda_{s, 0}$ is the zero-stress magnetostriction constant, and $B$ is a positive coefficient of order $10^{-10} \mathrm{MPa}$ and $\sigma$-stresses. Therefore, a decrease in 
$\lambda_{s}$ reported for Co-rich microwires $\left(\lambda_{s}<0\right)$ upon applied stresses [54,55] can be associated with the development of circumferential magnetic anisotropy in the outer shell [71]. Consequently, experimentally observed linear $H_{k}\left(\sigma_{a p p}\right)$ dependence can be explained considering Equations (2), (4), and (5). The influence of chemical etching on the hysteresis loops and on $H_{k}$ observed in Figures 2 and 3 is exactly the opposite to the effect of tensile stresses. Therefore, the theoretically predicted character of internal stresses with a dominant axial tensile character and its dependence on the $\rho$-ratio look reasonable. Accordingly, it is expected that the internal stresses value can be tuned by the glass-coating thickness through the $\rho$-ratio.

The correlation of the $\rho$-ratio and the hysteresis loops of Co-rich microwires with a vanishing magnetostriction coefficient is reported elsewhere [12,73-75]. For the case of $\mathrm{Co}_{67} \mathrm{Fe}_{3.85} \mathrm{Ni}_{1.45} \mathrm{~B}_{11.5} \mathrm{Si}_{14.5} \mathrm{Mo}_{1.7}$ microwires with vanishing magnetostriction coefficient (see Figure 6) linear, almost non-hysteretic loops with extremely low coercivities (up to $4 \mathrm{~A} / \mathrm{m}$ ) are observed. If we plot $H_{k}$ obtained from the hysteresis loops of $\mathrm{Co}_{67} \mathrm{Fe}_{3.85} \mathrm{Ni}_{1.45} \mathrm{~B}_{11.5} \mathrm{Si}_{14.5} \mathrm{Mo}_{1.7}$ microwires with various $d$ and $D$-values versus the $\rho$-ratio, we can find out that there is a correlation between these parameters. Magnetic anisotropy field, $H_{k}$, increases with decreasing the $\rho$-ratio (Figure $6 \mathbf{b}$ ).
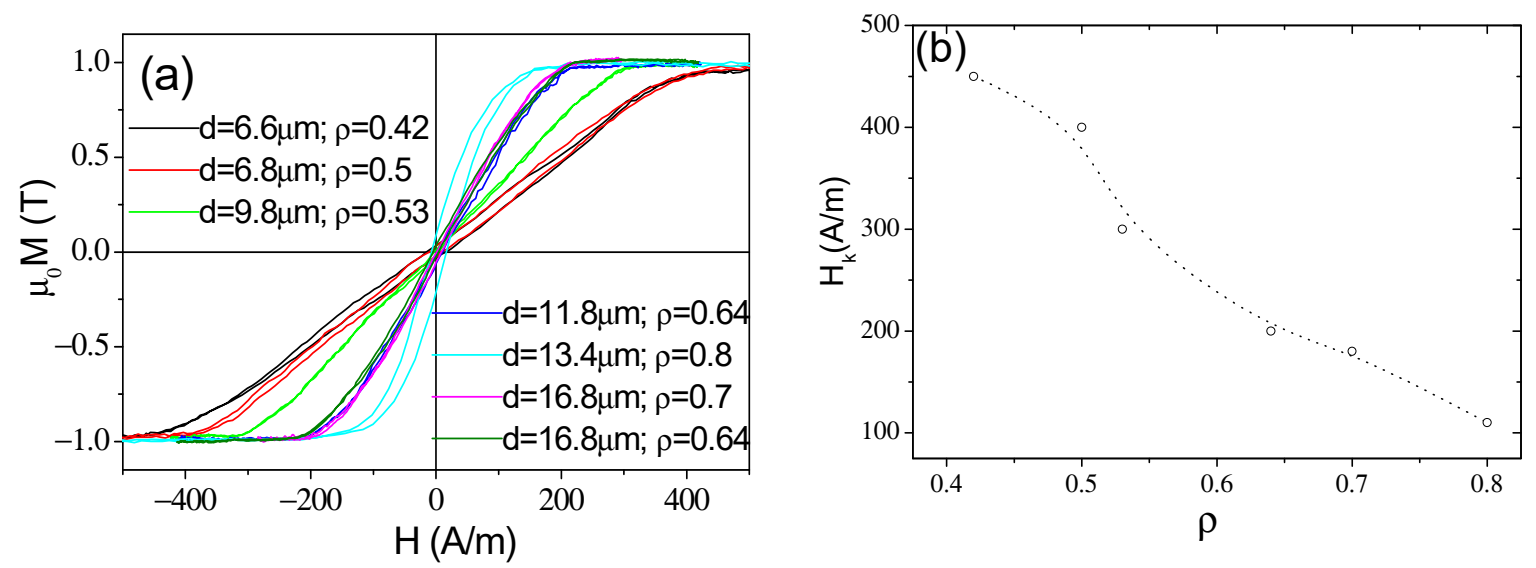

Figure 6. Hysteresis loops of $\mathrm{Co}_{67.1} \mathrm{Fe}_{3.8} \mathrm{Ni}_{1.4} \mathrm{Si}_{14.5} \mathrm{~B}_{11.5} \mathrm{Mo}_{1.7}$ microwires with different geometry (a) and $H_{k}(\rho)$ dependence for the same microwires $(\mathbf{b})$. (Reproduced with permission from [12] Copyright (C) 2015 Elsevier B.V.)

As mentioned above, glass-coated microwires with positive $\lambda_{s}$-value generally present perfectly rectangular hysteresis loops related to spontaneous magnetic bistability. A typical hysteresis loop of microwires with positive $\lambda_{s}$-value is shown in Figure 1a. Fast magnetization switching and related single DW propagation reported in magnetic micro- and nano-wires are proposed for various technical applications, like magnetic sensors, electronic surveillance, magnetic memories, and logics [7,75-77]. Thus, the method for magnetic codification using magnetic tags [75] is based on sharp voltage signals induced by fast magnetization switching of magnetically bistable microwires. In this application, each tag consists of several microwires with rectangular hysteresis loop and hence well-defined coercivities. Under an external AC magnetic field, each specific microwire in the tag is remagnetized in a different magnetic field, which leads to the appearance of an electrical signal in the detection system. Variety of coercivities allows for extending the number of combinations for magnetic codification. Therefore, tunability of coercivities, $H_{c}$, of magnetically bistabile microwires is essentially relevant for this application and has been extensively studied [46,78-80].

As can be appreciated from Figure 7 , even for the same microwire composition, $H_{c}$ can be changed by almost an order of magnitude (from 85 to $630 \mathrm{~A} / \mathrm{m}$ ) by adjusting the $\rho$-ratio. Similarly to the case of Co-rich microwires, $H_{c}$-values obtained for microwires with different $D$ and $d$-values can be represented by $H_{c}(\rho)$ dependence (i.e., $H_{c}$-values for different $D$ and $d$-values can be represented by $H_{c}(\rho)$ dependence (see Figure 7e). 


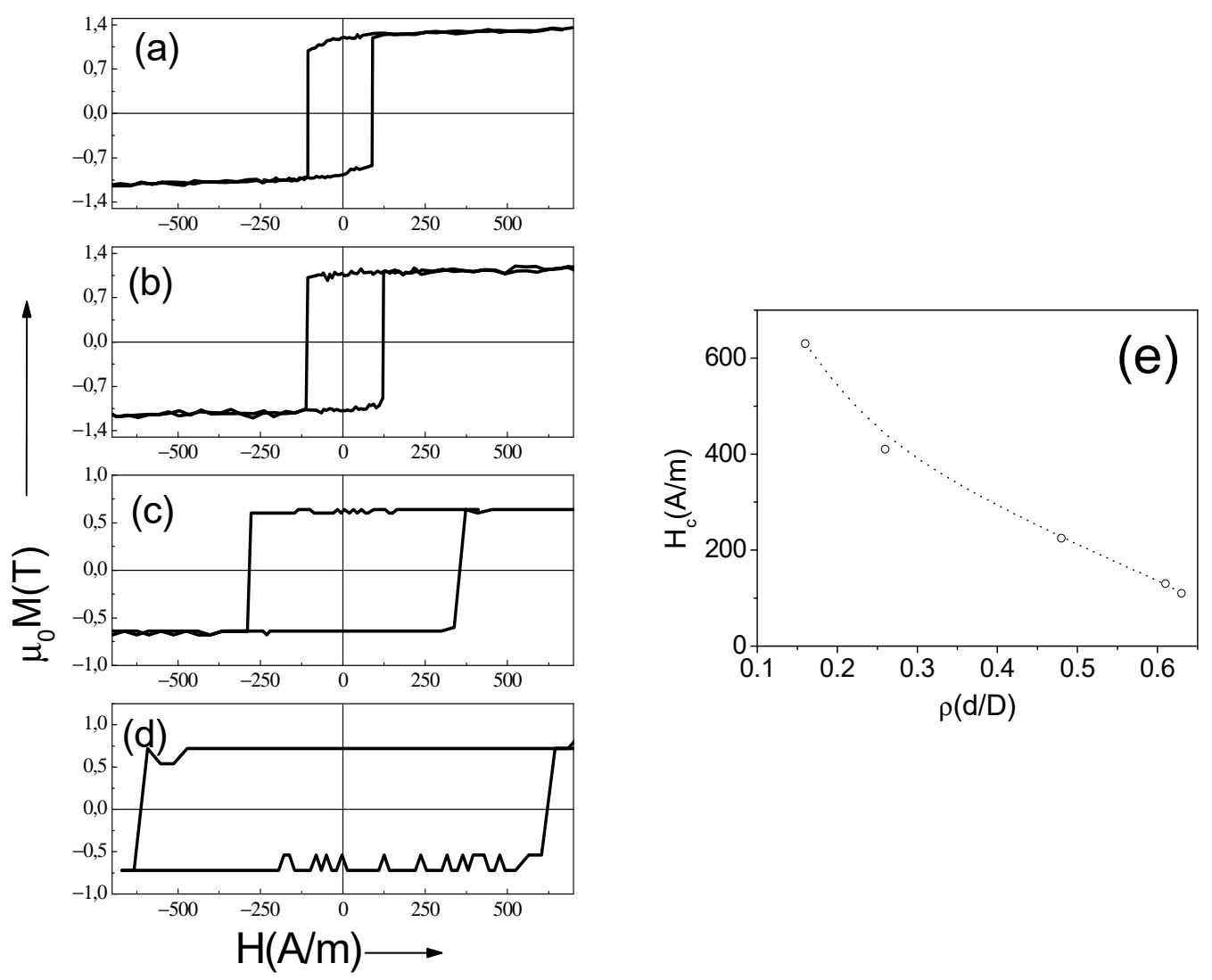

Figure 7. Hysteresis loops of $\mathrm{Fe}_{70} \mathrm{~B}_{15} \mathrm{Si}_{10} \mathrm{C}_{5}$ amorphous microwires with different metallic nucleus diameter $d$ and total diameters $D$ : with $\rho=0.63 ; d=15 \mu \mathrm{m}(\mathbf{a}) ; \rho=0.48 ; d=10.8 \mu \mathrm{m}(\mathbf{b}) ; \rho=0.26$; $d=6 \mu \mathrm{m}(\mathbf{c}) ; \rho=0.16 ; d=3 \mu \mathrm{m}(\mathbf{d})$ and $H_{c}(\rho)$ dependence of the same microwires (e). Adapted from [78].

Considering aforementioned results, one can expect that stresses relaxation by heat treatment can efficiently affect the magnetic properties of microwires.

One of the examples of annealing influence on hysteresis loops of Fe-rich microwires is shown in Figure 8.

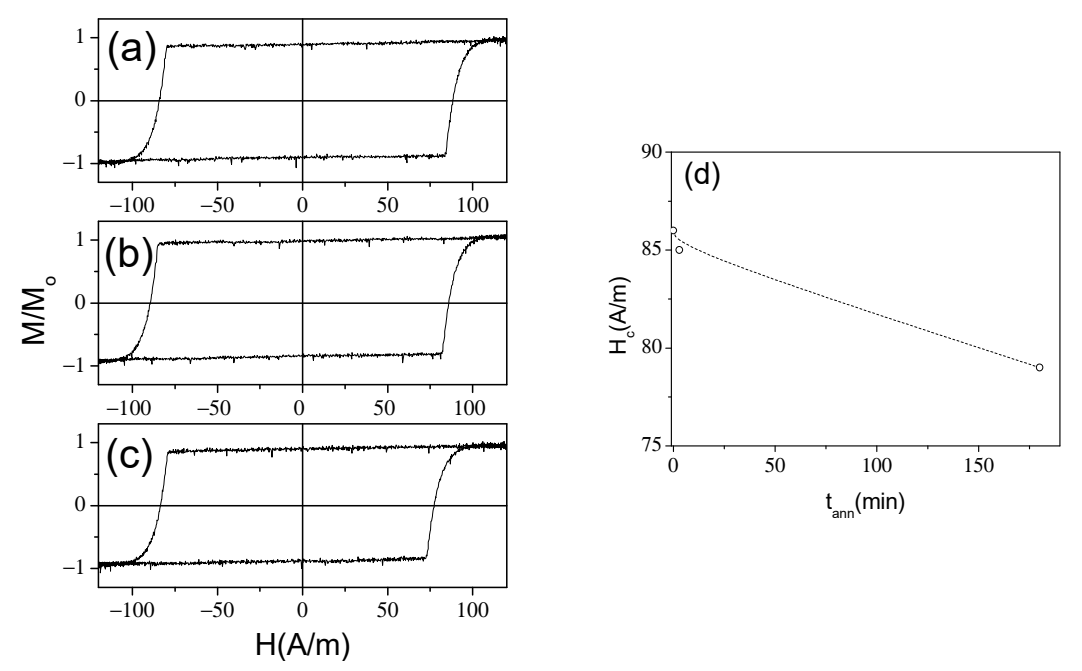

Figure 8. Hysteresis loops of as-prepared (a), and annealed at $T_{\text {ann }}=400{ }^{\circ} \mathrm{C}$ for $3 \mathrm{~min}(\mathbf{b})$ and $180 \mathrm{~min}$ (c) $\mathrm{Fe}_{75} \mathrm{~B}_{9} \mathrm{Si}_{12} \mathrm{C}_{4}$ microwires and dependence of coercivity on annealing time (d). 
For the $\mathrm{Fe}_{75} \mathrm{~B}_{9} \mathrm{Si}_{12} \mathrm{C}_{4}$ microwires, annealing does not affect the hysteresis loop character. However, a slight $H_{c}$ decrease is observed (see Figure 8b).

More complex behavior has been reported for Fe-Ni based microwires with positive magnetostriction and hence presenting spontaneous magnetic bistability [81,82].

As-prepared $\mathrm{Fe}_{62} \mathrm{Ni}_{15.5} \mathrm{Si}_{7.5} \mathrm{~B}_{15}$ microwires present rectangular hysteresis loops (see Figure 9a) as expected for microwires with positive $\lambda_{s}$-values (about $27 \times 10^{-6}$ ).

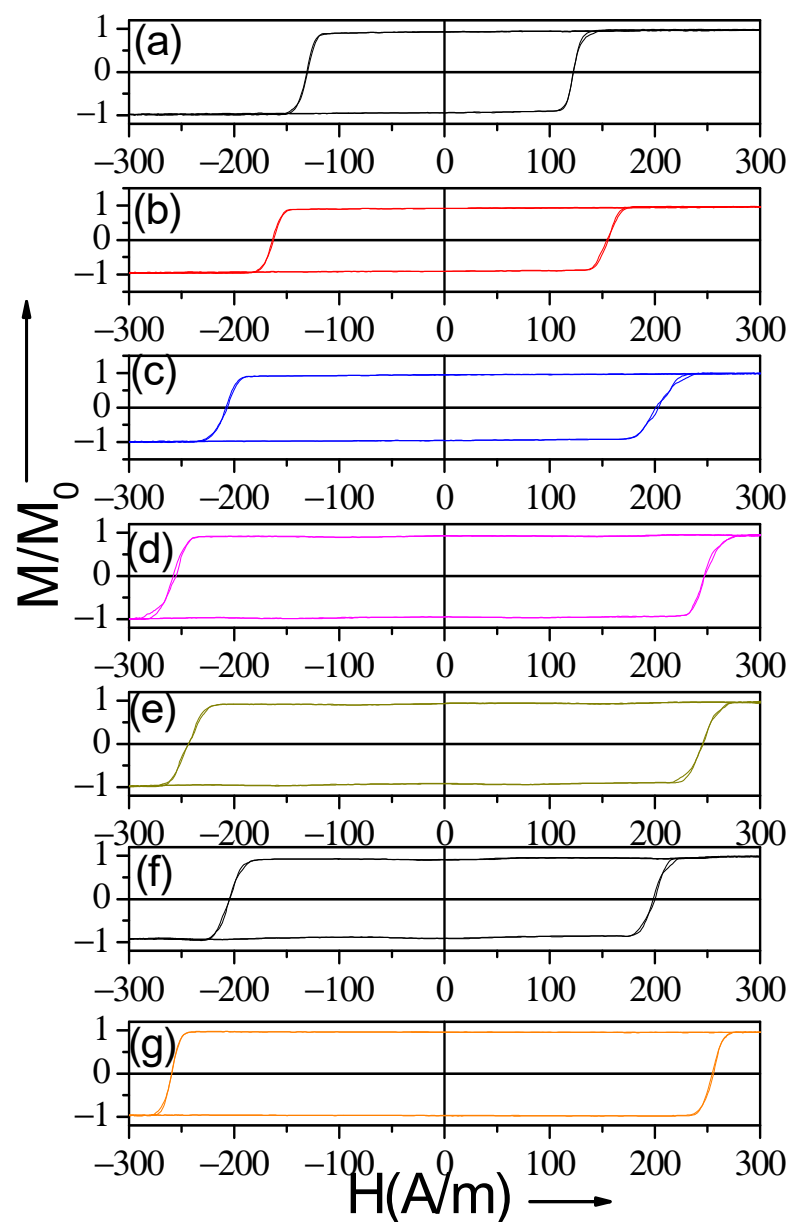

Figure 9. Hysteresis loops of as-prepared (a) and annealed at $T_{\text {ann }}=410{ }^{\circ} \mathrm{C}$ for $4 \mathrm{~min}(\mathbf{b}), 16 \mathrm{~min}$ (c) $32 \min (\mathbf{d}), 64 \mathrm{~min}(\mathbf{e}), 128 \mathrm{~min}(\mathbf{f})$, and $256 \mathrm{~min}(\mathrm{~g}) \mathrm{Fe}_{62} \mathrm{Ni}_{15.5} \mathrm{Si}_{7.5} \mathrm{~B}_{15}$ microwires. Adapted from [81].

After annealing, an increase in coercivity, $H_{c}$, is generally observed (see Figures $9 \mathbf{b}-\mathrm{g}$ and 10 ). The hysteresis loop character remains unchanged: all hysteresis loops present rectangular shape.

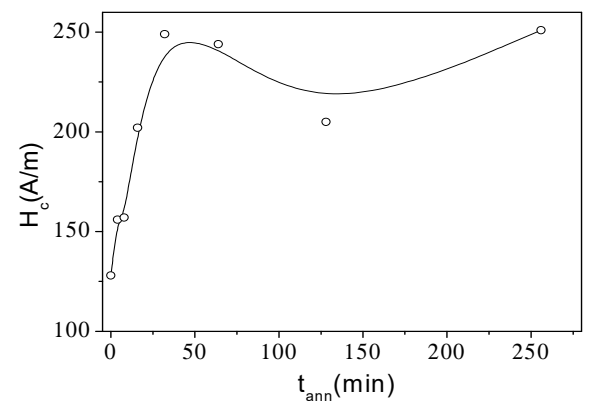

Figure 10. $H_{\mathcal{C}}\left(t_{\text {ann }}\right)$ dependence evaluated in $\mathrm{Fe}_{62} \mathrm{Ni}_{15.5} \mathrm{Si}_{7.5} \mathrm{~B}_{15}$ microwires. (Reproduced with permission from [81] Figure 2d Copyright (C 2020 AIP Publishing LLC, Open Access). 
Although generally higher $H_{\mathcal{C}}$-values are observed in annealed samples, $H_{\mathcal{c}}\left(t_{\text {ann }}\right)$ dependence is not monotonic: for $t_{a n n}=128 \mathrm{~min}$ some $H_{c}$ decrease is observed (see Figure 10).

Similarly, the second Fe-Ni based $\left(\mathrm{Fe}_{49.6} \mathrm{Ni}_{27.9} \mathrm{Si}_{7.5} \mathrm{~B}_{15}\right)$ microwire presents rectangular hysteresis loops in as-prepared state and after annealing (see Figure 11). Lower $H_{c}$-values observed in as-prepared $\mathrm{Fe}_{49.6} \mathrm{Ni}_{27.9} \mathrm{Si}_{7.5} \mathrm{~B}_{15}$ microwire can be related to lower $\lambda_{s}$-values of $\mathrm{Fe}_{49.6} \mathrm{Ni}_{27.9} \mathrm{Si}_{7.5} \mathrm{~B}_{15}$ microwires $\left(\lambda_{s} \approx 20 \times 10^{-6}\right)[54,55]$. However, $H_{c}\left(t_{a n n}\right)$ dependence is different from that showed by $\mathrm{Fe}_{62} \mathrm{Ni}_{15.5} \mathrm{Si}_{7.5} \mathrm{~B}_{15}$ microwire: upon annealing (at the same conditions, i.e., $T_{\text {ann }}$ and $t_{\text {ann }}$ ) first a slight decrease in $H_{c}$ followed by $H_{c}$ rising is observed (see Figure 11e).

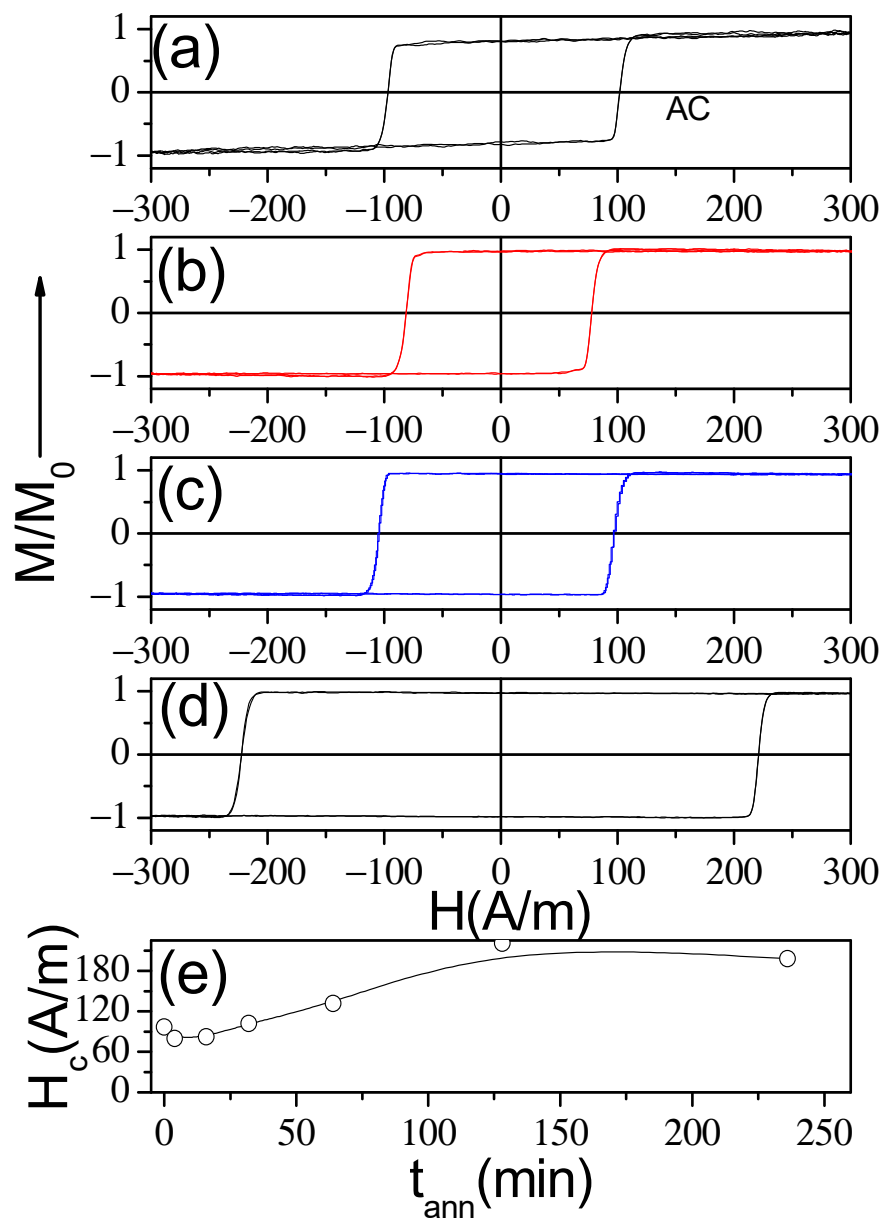

Figure 11. Hysteresis loops of as-prepared (a) and annealed at $T_{\text {ann }}=410^{\circ} \mathrm{C}$ for $t_{\text {ann }}=4 \min (\mathbf{b})$ $32 \min (\mathbf{c}) 128 \mathrm{~min}(\mathbf{d})$ and $H_{c}\left(t_{a n n}\right)$ dependence (e) for $\mathrm{Fe}_{49.6} \mathrm{Ni}_{27.9} \mathrm{Si}_{7.5} \mathrm{~B}_{15}$ microwires. (Reproduced with permission from [81] Copyright (C) 2020 AIP Publishing LLC, Open Access).

Considering that the annealing is the common route for the internal stresses relaxation, an observed annealing effect on $H_{c}$ in Fe-Ni microwires looks unexpected. For explanation of a rather different effect of annealing on coercivity of Fe and Fe-Ni based microwires, different factors such as the beginning of crystallization process or domain wall stabilization due to directional ordering of atomic pairs being considered [81-84].

From our previous studies, we must disregard the crystallization process, since Fe-Ni based microwires annealed at the same $T_{a n n}$ for $8 \mathrm{~h}$ still present amorphous structure [85]. Therefore, for interpretation of observed $H_{\mathcal{C}}\left(t_{\text {ann }}\right)$ dependencies in Fe-Ni based microwires, several phenomena can be considered. One of these phenomena is local atomic environment changes in an amorphous structure related to annealing and clustering. Indeed, local nano-sized precipitations have been observed in annealed Fe-Ni based microwires by the atom probe tomography [85]. 
Furthermore, atom pair ordering and hence DW stabilization is reported for Fe-Ni and Fe-Co amorphous alloys [81-84,86,87].

Such DW stabilization is considered as the main origin of the $H_{\mathrm{c}}$ rising upon annealing observed in amorphous materials containing two or more ferromagnetic elements [88,89]. Such magnetic hardening is usually reported for annealing temperature below Curie temperature, $T_{c}$. This mechanism can explain the difference in annealing influence on coercivity in Fe-based and Fe-Ni based microwires. In addition, the Curie temperature, $T_{c}$, of $\mathrm{Fe}_{49.6} \mathrm{Ni}_{27.9} \mathrm{Si}_{7.5} \mathrm{~B}_{15}$ amorphous alloys is about $400{ }^{\circ} \mathrm{C}$, being considerably lower than that for $\mathrm{Fe}_{62} \mathrm{Ni}_{15.5} \mathrm{Si}_{7.5} \mathrm{~B}_{15}$ alloy [90]. Accordingly, the DW stabilization for $\mathrm{Fe}_{62} \mathrm{Ni}_{15.5} \mathrm{Si}_{7.5} \mathrm{~B}_{15}$ microwire is expected to be more relevant than that for the $\mathrm{Fe}_{49.6} \mathrm{Ni}_{27.9} \mathrm{Si}_{7.5} \mathrm{~B}_{15}$ microwire and hence the internal stresses relaxation plays a major role in the alloy with lower $T_{c}$.

Additionally, the internal stresses relaxation upon annealing (evidenced by a $H_{c}$ decrease in Fe-rich microwires, see Figure 8$)$ is another factor influencing the $H_{c}\left(t_{\text {ann }}\right)$ dependencies of microwires. However, chemical composition of $\mathrm{Fe}_{49.6} \mathrm{Ni}_{27.9} \mathrm{Si}_{7.5} \mathrm{~B}_{15}$ microwire is similar to the Invar-like composition (Ni/Fe content about 40/60) [82]. The peculiarity of the Invar-like crystalline materials with Ni/Fe content about $40 / 60$ is that they can present the Invar anomaly, i.e., low thermal expansion coefficient [91]. The Invar anomaly is intrinsically related to the local atomic structure of Fe-Ni alloys. Considering similarity of short range order of amorphous and crystalline materials [92], one can expect lower internal stresses influence in the $\mathrm{Fe}_{49.6} \mathrm{Ni}_{27.9} \mathrm{Si}_{7.5} \mathrm{~B}_{15}$ microwire.

In spite of observed magnetic hardening of Fe-Ni based microwires upon annealing, observed experimental dependencies allows for tuning the coercivity value by annealing.

Even more remarkable hardening upon conventional annealing has been reported in a variety of Co-rich microwires with vanishing $\lambda_{s}$-values [49,93]. Thus, transformation of linear hysteresis loop with low coercivity $\left(H_{c} \approx 4 \mathrm{~A} / \mathrm{m}\right)$ into rectangular with $H_{c} \approx 90 \mathrm{~A} / \mathrm{m}$ and considerable magnetic hardening are observed in $\mathrm{Fe}_{3.6} \mathrm{Co}_{69.2} \mathrm{Ni}_{1} \mathrm{~B}_{12.5} \mathrm{Si}_{11} \mathrm{Mo}_{1.5} \mathrm{C}_{1.2}$ microwire upon annealing without stress (see Figure 12). Gradual squareness ratio, $M_{r} / M_{0}$, rising upon $T_{\text {ann }}$ increasing can be appreciated, although $\mathrm{Fe}_{3.6} \mathrm{Co}_{69.2} \mathrm{Ni}_{1} \mathrm{~B}_{12.5} \mathrm{Si}_{11} \mathrm{Mo}_{1.5} \mathrm{C}_{1.2}$ microwires annealed at different $T_{\text {ann }}$ present similar coercivity.

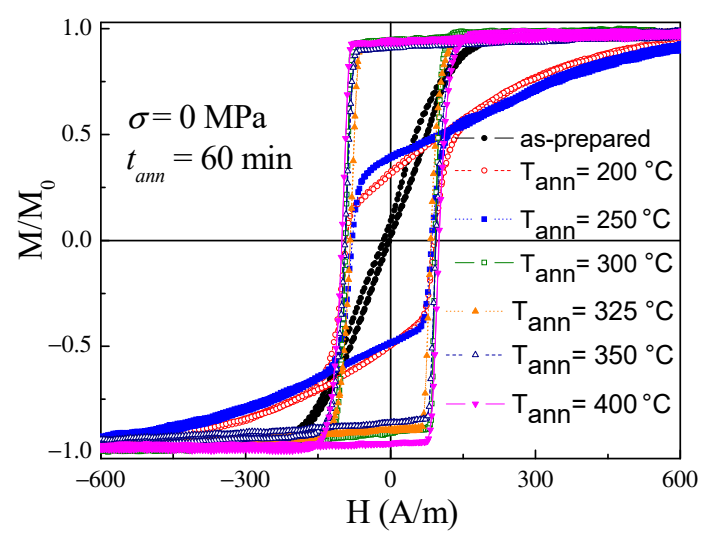

Figure 12. Hysteresis loop of the $\mathrm{Fe}_{3.6} \mathrm{Co}_{69.2} \mathrm{Ni}_{1} \mathrm{~B}_{12.5} \mathrm{Si}_{11} \mathrm{Mo}_{1.5} \mathrm{C}_{1.2}$ microwires annealed without stress at different temperatures. (Reproduced with permission from [49] Copyright (C) 2020 Elsevier B.V.)

Observed behavior of $M_{r} / M_{o}$ upon annealing must be attributed to rising of the inner axially magnetized inner core diameter. Using relation (3) between the radius of the inner axially magnetized core, $R_{c}$, and $M_{r} / M_{0}$, one can obtain $R_{c}\left(T_{a n n}\right)$ dependence (see Figure 13). Observed modification of the hysteresis loops shape and obtained $R_{c}\left(T_{a n n}\right)$ dependence are consistent with the evolution of the hysteresis loop shape upon glass-coating removal by chemical etching (see Figures 3 and 4 ). Accordingly, $R_{c}\left(T_{a n n}\right)$ dependence and observed evolution of the hysteresis loops upon annealing must be related to the relaxation of internal stresses as discussed elsewhere [74,93-95]. 


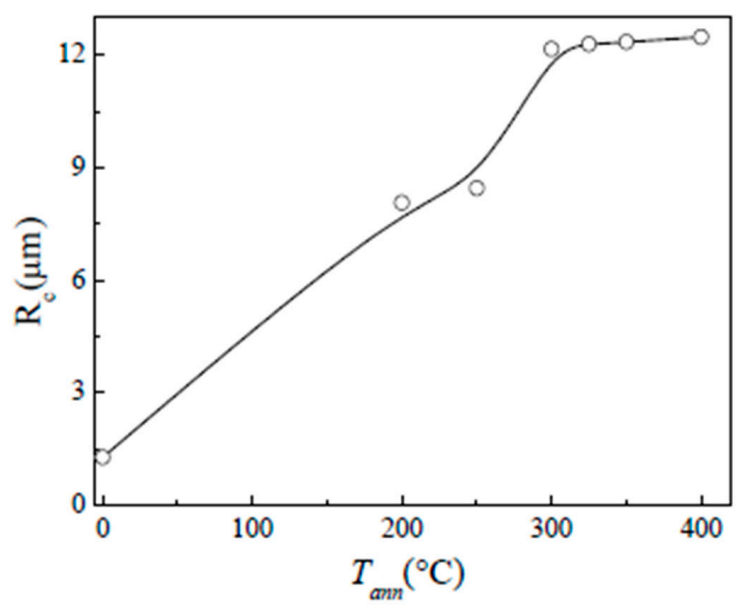

Figure 13. Dependence of radius of inner axially magnetized core, $R_{c}$, on annealing temperature, $T_{\text {ann }}$, in studied microwire. (Reproduced with permission from [49] Copyright (C) 2020 Elsevier B.V.)

Such evolution of hysteresis loops upon annealing is confirmed in various Co-based microwires with low and negative $\lambda_{s}$-values [93-96]. One more example for another Co-rich $\left(\mathrm{Co}_{69.2} \mathrm{Fe}_{4.1} \mathrm{~B}_{11.8} \mathrm{Si}_{13.8} \mathrm{C}_{1.1}\right)$ microwire with low negative $\lambda_{s}$-values is shown in Figure 14 . In this case, the annealing temperature was fixed $\left(T_{a n n}=250^{\circ} \mathrm{C}\right)$ and the hysteresis loops have been recorded at different annealing time, $t_{a n n}$. Similarly to the case of $\mathrm{Fe}_{3.6} \mathrm{Co}_{69.2} \mathrm{Ni}_{1} \mathrm{~B}_{12.5} \mathrm{Si}_{11} \mathrm{Mo}_{1.5} \mathrm{C}_{1.2}$ microwires, we can observe a remarkable $H_{c}$ rising and gradual $M_{r} / M_{0}$, increase with an increase in $t_{\text {ann }}$ (see Figure 15). Accordingly, from $R_{c}\left(t_{a n n}\right)$ evaluated from $M_{r} / M_{o}$, we can again observe a gradual increase of the inner axially magnetized domain radius upon annealing.
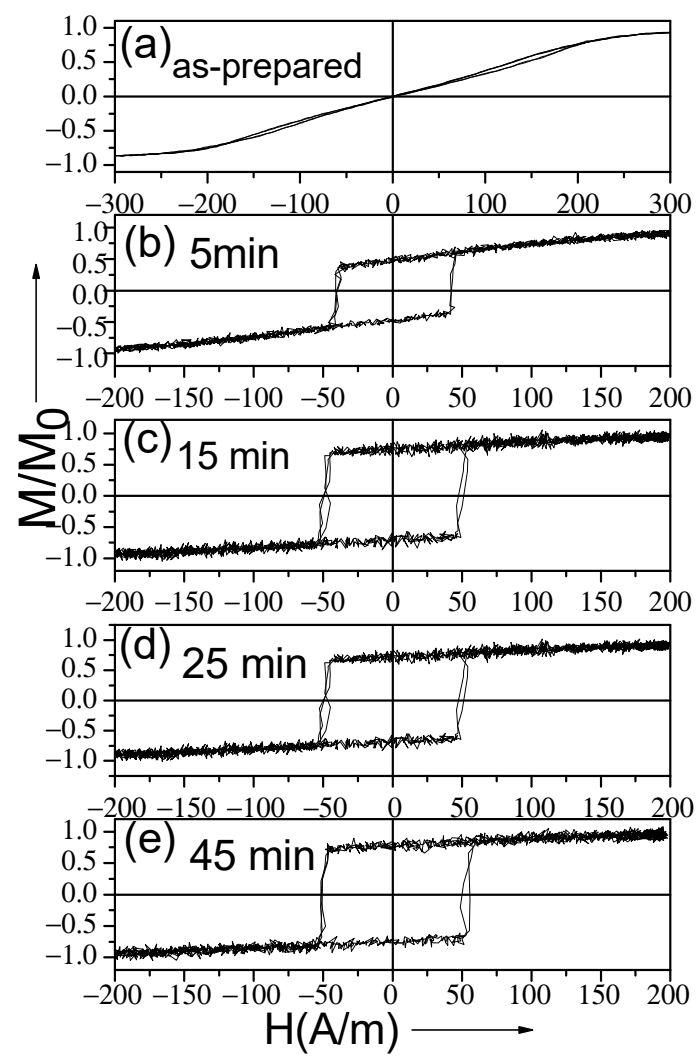

Figure 14. The hysteresis loops of as-prepared (a) and annealed for 5 (b), 15 (c), 25 (d) and 45 (e) $\mathrm{min}$ $\mathrm{Co}_{69.2} \mathrm{Fe}_{4.1} \mathrm{~B}_{11.8} \mathrm{Si}_{13.8} \mathrm{C}_{1.1}$ microwires annealed at $T_{\text {ann }}=250{ }^{\circ} \mathrm{C}$. Adapted from [96] Copyright (C) 2014 Springer Nature. 

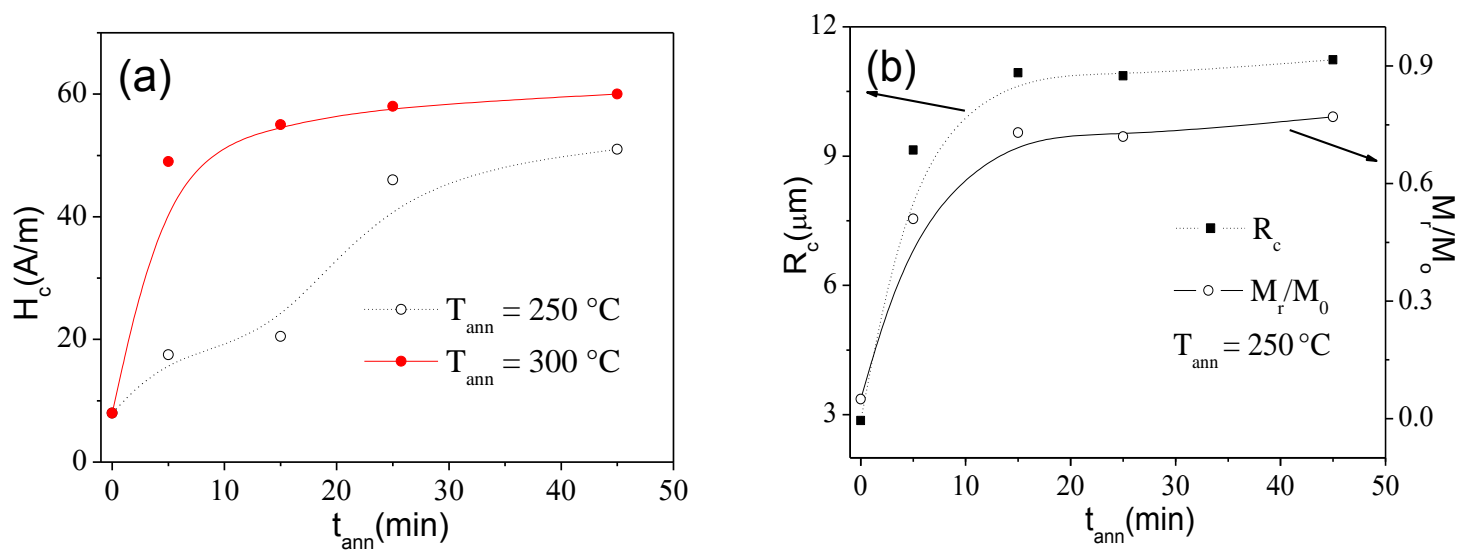

Figure 15. Dependence of coercivity, $H_{c}$, (a) and reduced remanent magnetization, $M_{r} / M_{H \max }$ (b) on annealing time, $t_{\text {ann }}$ in $\mathrm{Co}_{69.2} \mathrm{Fe}_{4.1} \mathrm{~B}_{11.8} \mathrm{Si}_{13.8} \mathrm{C}_{1.1}$ microwires. Adapted from [96] Copyright (c) 2014 Springer Nature.

Consequently, similarly to glass-coating removal, annealing of Co-rich microwires allows for obtaining magnetically bistable Co-rich microwires. Such Co-rich microwires with magnetic bistability induced by annealing present fast magnetization switching by propagation of single domain wall, similarly to Fe-rich microwires [60]. However, magnetic properties of either annealed or chemically etched Co-rich microwires are similar to those of Fe-rich microwires: the coercivity values of either annealed or chemically etched Co-based microwires are almost an order of magnitude higher than those of as-prepared Co-based microwires.

Therefore, optimization of the magnetic softness of amorphous microwires requires development of special post-processing. One of the promising routes allowing achievement of better magnetic softness is controllable magnetic anisotropy induction. Below, we will present several examples of thermal treatment allowing magnetic properties optimization of magnetic microwires.

\subsection{Effect of Induced Magnetic Anisotropy on Hysteretic Magnetic Properties of Amorphous} Glass-Coated Microwires

Considering new functional properties provided by insulating and flexible glass-coating, most attention has been paid to tuning of the hysteresis loops of Fe-Co-Ni- based microwires by appropriate annealing. As shown above, conventional annealing provides limited possibilities for tuning the hysteresis loops. Accordingly, several attempts have been performed recently to search more efficient post-processing allowing tuning the magnetic properties [43,52,97].

One of the most promising and effective methods for tuning of the magnetic properties of magnetic microwires is stress-annealing. In the case of magnetic microwires with a positive magnetostriction coefficient, this post-processing allows remarkable magnetic softness improvement [43,52,86,87,94,95].

From previous knowledge on the origin of induced magnetic anisotropy, it is known that the magnetic anisotropy of amorphous materials can be effectively tailored by either stress or magnetic field annealing [83,84].

Recently, stress-annealing has been successfully employed for tailoring of magnetic properties in glass-coated microwires. Thus, according to several publications on the origin of the induced anisotropy in glass-coated microwires $[74,86,87,98]$, the presence of the glass-coating can be even beneficial for tuning the magnetic anisotropy.

Several examples on the influence of stress-annealing on magnetic properties of glass-coated microwires are provided below.

From Figure 16, we can clearly see that stress-annealing performed in the same conditions ( $T_{a n n}$ and $t_{a n n}$ ) allows better magnetic softening and transverse anisotropy induction in Fe-based $\left(\mathrm{Fe}_{75} \mathrm{~B}_{9} \mathrm{Si}_{12} \mathrm{C}_{4}\right)$ microwires. As reported elsewhere $[87,98]$, such transverse anisotropy depends on various parameters, like $T_{a n n}, t_{a n n}$, and stress, $\sigma_{m}$, applied during the annealing [87]. A clear example 
is shown in Figure 17. As can be appreciated from Figure 17, for high enough $T_{\text {ann }}$ or $\sigma_{m}$, a remarkable transverse magnetic anisotropy can be induced.
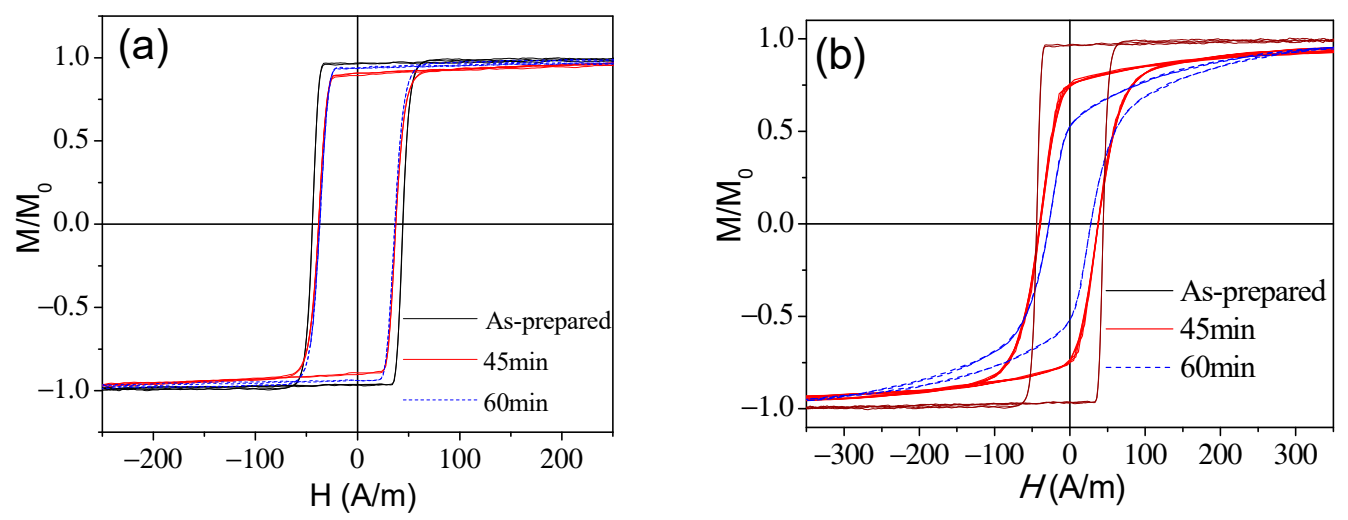

Figure 16. Hysteresis loops of as-prepared and annealed at $T_{a n n}=325^{\circ} \mathrm{C}$ (a) and as-prepared and stress-annealed at $T_{a n n}=325^{\circ} \mathrm{C}$ and $\sigma_{m}=190 \mathrm{MPa}(\mathbf{b}) \mathrm{Fe}_{75} \mathrm{~B}_{9} \mathrm{Si}_{12} \mathrm{C}_{4}$ microwire. Adapted from [98].

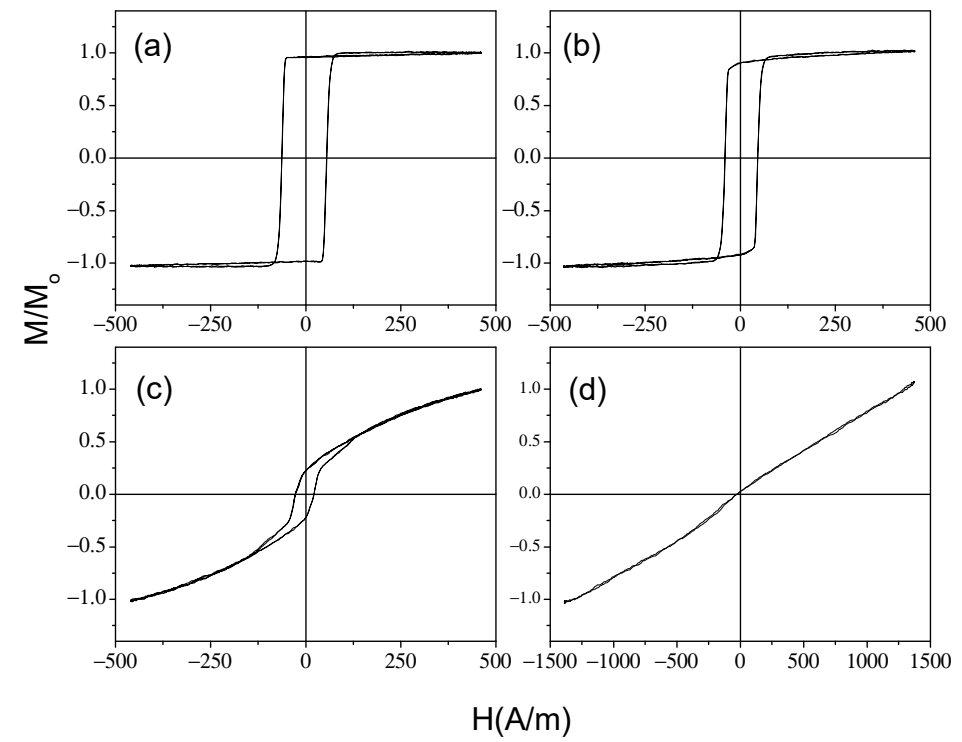

Figure 17. Hysteresis loops of as-prepared (a), annealed at $200{ }^{\circ} \mathrm{C}(\mathbf{b}), 250{ }^{\circ} \mathrm{C} \mathrm{(c)} \mathrm{and} 300{ }^{\circ} \mathrm{C}(\mathbf{d})$ for $1 \mathrm{~h}$ and $\sigma_{m} \approx 900 \mathrm{MPa} \mathrm{Fe}{ }_{75} \mathrm{~B}_{9} \mathrm{Si}_{12} \mathrm{C}_{4}$ microwires. (Reproduced with permission from [87] Copyright (C) 2018, Springer Nature, Open Access).

However, for low enough $T_{a n n}, t_{a n n}$, or $\sigma_{m}$, the hysteresis loops maintain rectangular shape (see Figure 18a) and can present all the features typical for magnetically bistable microwires, i.e., fast and single domain wall propagation [98]. Lower coercivity is generally observed in stress-annealed Fe-rich microwires (see Figure 18a,b). Consequently, stress annealing allows for more effectively tuning $H_{\mathrm{c}}$ and $M_{r} / M_{o}$-values (see Figure 18c). However, for sufficiently high $T_{a n n}, t_{a n n}$, or $\sigma_{m}$ the hysteresis loops of Fe-rich microwires become inclined (similar to that of as-prepared Co-rich microwires) with clear transverse magnetic anisotropy (see Figures $17 \mathrm{~d}$ and 18b). As recently reported [42,43,86,87], such Fe-rich microwires with stress-induced transverse magnetic anisotropy present better GMI response as well as GMI effect and hysteresis loops sensitive to applied stresses [99,100]. Therefore, such microwires can be suitable for development of magnetic sensors based on GMI effect or for magnetoelastic sensors [32,71]. 

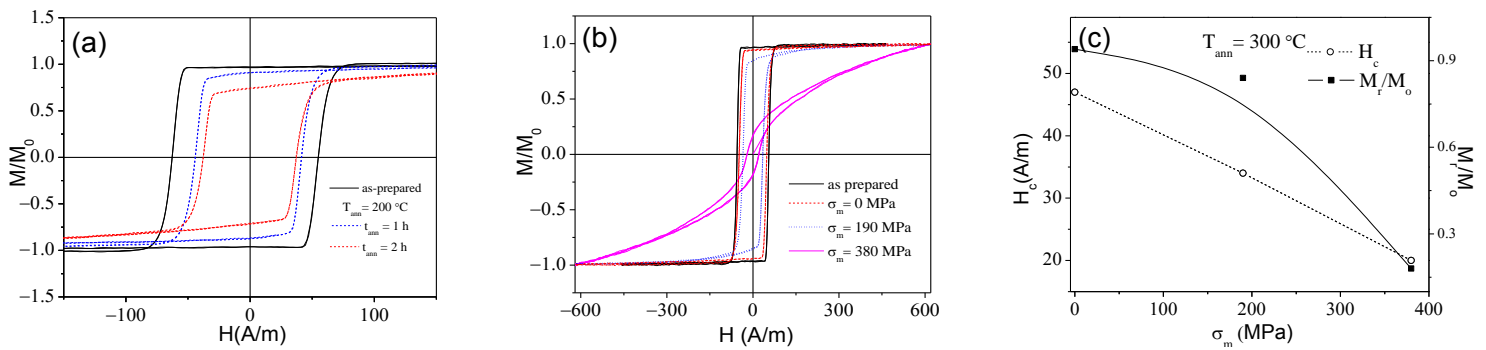

Figure 18. Hysteresis loops of as-prepared and stress-annealed at $T_{\text {ann }}=200{ }^{\circ} \mathrm{C}, \sigma \approx 900 \mathrm{MPa}$ for different $t_{a n n}(\mathbf{a})$, effect of tensile stress applied during the annealing at $T_{\text {ann }}=300{ }^{\circ} \mathrm{C}$ on hysteresis loops (b) and $H_{\mathrm{c}}$ and $M_{r} / M_{0}$ values (c) of $\mathrm{Fe}_{75} \mathrm{~B}_{9} \mathrm{Si}_{12} \mathrm{C}_{4}$ microwires. Figure 18a is adapted from [87] Figure 2 (Copyright (C) 2018, Springer Nature, Open Access).

In the case of Co-based microwires higher annealing temperature, time or stresses are required to prevent magnetic hardening associated with relaxation of internal stresses related to glass-coating $[42,43,101]$. As can be observed in Figures 19 and 20, for extended range of $T_{a n n}, t_{a n n}$ or $\sigma_{m}$, stress-annealed Co-rich microwires present rectangular hysteresis loops. Therefore, stress-annealing of Co-rich microwires allows for tuning their coercivity in quite extended range. Thus, in certain stress-annealing conditions, $\mathrm{Co}_{68.7} \mathrm{Fe}_{4} \mathrm{Ni}_{1} \mathrm{~B}_{13} \mathrm{Si}_{11} \mathrm{Mo}_{2.3}$ microwires with rectangular hysteresis loops and extremely low coercivity of about $1 \mathrm{~A} / \mathrm{m}$ can be obtained (see Figure 21) [102].
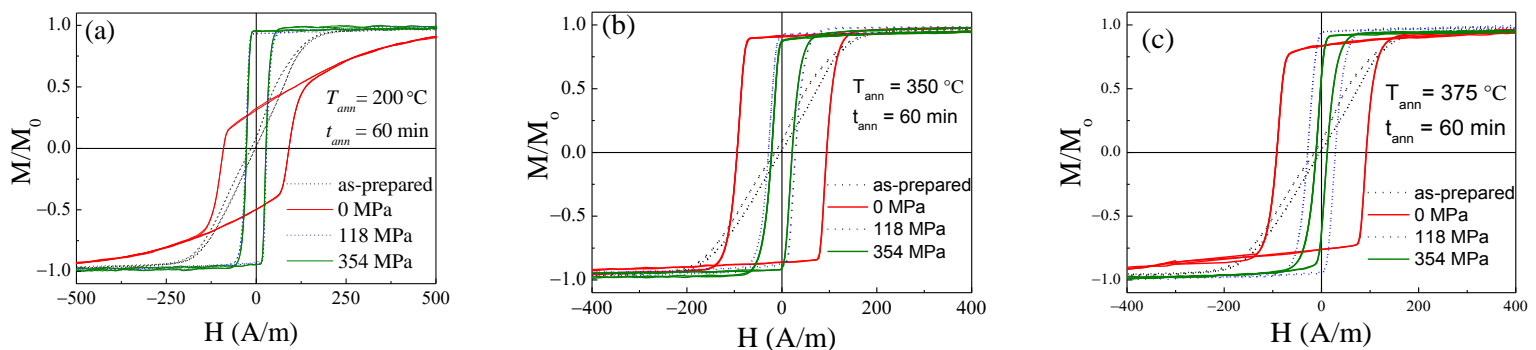

Figure 19. Hysteresis loops of $\mathrm{Fe}_{3.6} \mathrm{Co}_{69.2} \mathrm{Ni}_{1} \mathrm{~B}_{12.5} \mathrm{Si}_{11} \mathrm{Mo}_{1.5} \mathrm{C}_{1.2}$ microwires stress-annealed at different conditions: $T_{a n n}=200{ }^{\circ} \mathrm{C}(\mathbf{a}), T_{a n n}=350{ }^{\circ} \mathrm{C}(\mathbf{b})$ and $T_{a n n}=375^{\circ} \mathrm{C}(\mathbf{c})$. (Reproduced with permission from [49] Figure 7 Copyright (C) 2020 Elsevier B.V.)
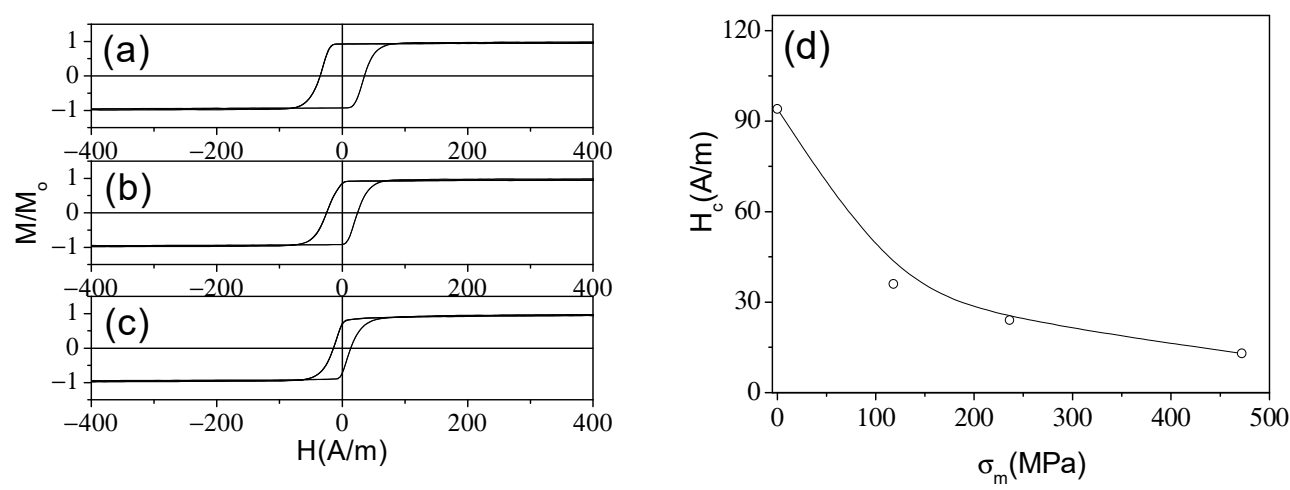

Figure 20. Hysteresis loops of $\mathrm{Fe}_{3.6} \mathrm{Co}_{69.2} \mathrm{Ni}_{1} \mathrm{~B}_{12.5} \mathrm{Si}_{11} \mathrm{Mo}_{1.5} \mathrm{C}_{1.2}$ microwires annealed at $\mathrm{T}_{\mathrm{ann}}=300{ }^{\circ} \mathrm{C}$ for $t_{\text {ann }}=1 \mathrm{~h}$ under $\sigma_{m}=118(\mathbf{a}), \sigma_{m}=236(\mathbf{b})$ and $\sigma_{m}=472 \mathrm{MPa}(\mathbf{c})$ and $H_{c}\left(\sigma_{m}\right)$ dependence at $T_{\text {ann }}=300^{\circ} \mathrm{C}$ for $t_{\text {ann }}=1 \mathrm{~h}(\mathbf{d})$. 

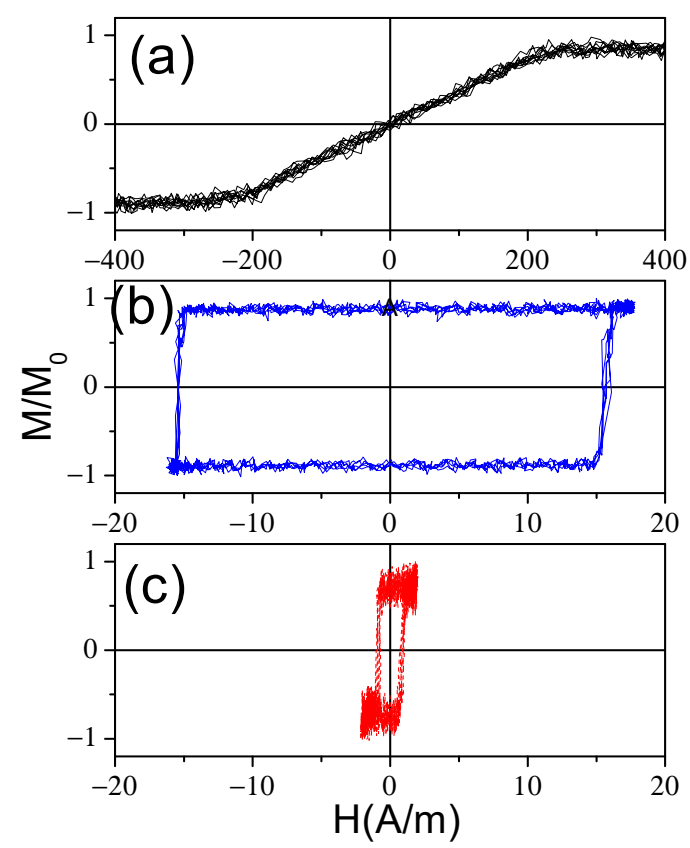

Figure 21. Hysteresis loops of as-prepared (a), annealed at $\mathrm{T}_{\mathrm{ann}}=350{ }^{\circ} \mathrm{C}(\mathbf{b})$ and stress annealed at $\mathrm{T}_{\mathrm{ann}}=350{ }^{\circ} \mathrm{C}$ and $\sigma_{m}=250 \mathrm{MPa}(\mathrm{c}) \mathrm{Co}_{68.7} \mathrm{Fe}_{4} \mathrm{Ni}_{1} \mathrm{~B}_{13} \mathrm{Si}_{11} \mathrm{Mo}_{2.3}$ microwires. Adapted from Ref. [102].

For sufficiently high $T_{a n n}, t_{a n n}$ or $\sigma_{m}$-values linear hysteresis loop of $\mathrm{Fe}_{3.6} \mathrm{Co}_{69.2} \mathrm{Ni}_{1} \mathrm{~B}_{12.5} \mathrm{Si}_{11} \mathrm{Mo}_{1.5} \mathrm{C}_{1.2}$ microwires can be recovered (see Figure 19). However, $T_{a n n}, t_{a n n}$ or $\sigma_{m}$-values at which transverse magnetic anisotropy in Co-rich microwires can be induced are considerably higher than those for Fe-rich microwires.

One more efficient method for tuning of hysteresis loops of Co-rich microwires, preventing excessive magnetic hardening, is the Joule heating (see Figure 22) [29]. In this case, the current flowing through the microwires produce heating itself as well as the circumferential magnetic field, $H_{\text {circ }}$ (associated with the current $I$ flowing through the sample) $[29,103]$.
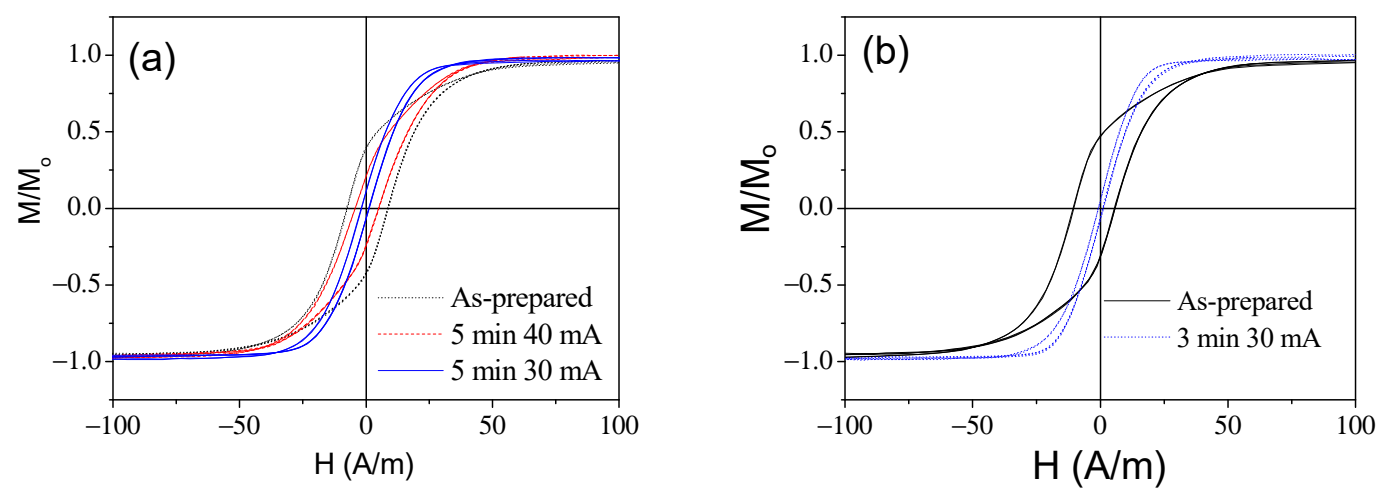

Figure 22. Hysteresis loops of as-prepared and current annealed at $30 \mathrm{~mA}$ and $40 \mathrm{~mA}$ for $5 \mathrm{~min}$ (a), $3 \mathrm{~min}$ and $30 \mathrm{~mA}(\mathbf{b}) \mathrm{Co}_{67} \mathrm{Fe}_{3.9} \mathrm{Ni}_{1.5} \mathrm{~B}_{11.5} \mathrm{Si}_{14.5} \mathrm{Mo}_{1.6}$ amorphous glass-coated microwire. (Reproduced with permission from [26] Copyright (C) 2019 Elsevier B.V.)

The aforementioned circumferential magnetic field, $H_{\text {circ }}$, produced by the current (Oersted field) in the surface of the metallic nucleus can be evaluated from the formula $[29,86]$ :

$$
H_{\text {circ }}=I / 2 \pi r
$$

where $I$ is the current value, $r$-radial distance. 
Magnetic softening obtained at certain conditions of Joule heating is evidenced by Figure 22 where the effect of Joule heating on hysteresis loops of $\mathrm{Co}_{67} \mathrm{Fe}_{3.9} \mathrm{Ni}_{1.5} \mathrm{~B}_{11.5} \mathrm{Si}_{14.5} \mathrm{Mo}_{1.6}$ microwire is shown. In this case, the microwires were heated by a DC current, I, of 30 and $40 \mathrm{~mA}$. These conditions were selected in order to avoid the crystallization and related deterioration of the magnetic properties. In the case of Joule heating, the current density is one of the main parameters determining the sample heating [104]. Although the thickness of the glass coating and the metallic nucleus diameter also affect the heat transfer rate [40]. In the given case, the current densities (58.3 and $77.7 \mathrm{~A} / \mathrm{mm}^{2}$ for 30 and $40 \mathrm{~mA}$, respectively) are well below the value that can produce magnetic hardening related to the crystallization [104].

Observed magnetic softening is related to the presence of magnetic field that can considerably affect the magnetic anisotropy of amorphous materials [105]. It was reported that the macroscopic magnetic anisotropy of amorphous materials is originated by a preferred magnetization direction during the annealing and was discussed in terms of either the directional ordering of atomic pairs or compositional and topological short-range ordering [83-85,93-95,105].

\subsection{Tuning of Hysteretic Magnetic Properties in Crystalline and Devitrified Glass-Coated Microwires}

The devitrification of amorphous nucleus reached by post annealing process is another useful tool allowing considerable modification of the magnetic properties and even magnetic softening in some Fe-rich microwires [48].

In the case of FeSiBNbCu (so-called Finemet) alloys, low magnetostriction values and better magnetic softness can be achieved by the devitrification of the amorphous precursor [57]. The magnetic softening of the devitrified Finemet alloys is commonly explained considering the vanishing magnetocrystalline anisotropy, as well as the vanishing $\lambda_{s}$-value of the material, consisting of nano-sized grains with an average size on the order of $10 \mathrm{~nm}$, embedded in an amorphous matrix obtained by nanocrystallization of the amorphous precursors [57].

The average magnetostriction coefficient takes nearly-zero values [57,106], due to the control of the crystalline volume fraction: the existence of two phases (amorphous and crystalline) provides a good balance of a negative magnetostriction of $\alpha$-Fe-Si nanocrystallites of about $\left(\lambda_{s}^{\mathrm{FeSi}} \approx-6 \times 10^{-6}\right)$ [48] and a positive one for the amorphous matrix of about $\left(\lambda_{s}^{a m} \approx 20 \times 10^{-6}\right)$ [48] resulting finally in vanishing net magnetostriction values [105]:

$$
\lambda_{s}^{e f f} \approx V_{c r} \lambda_{s}^{F e S i}+\left(1-V_{c r}\right) \lambda_{s}^{a m}
$$

where $\lambda_{s}{ }^{e f f}$ is the saturation magnetostriction coefficient, and $V_{c r}$ is the crystalline volume fraction.

This nanocrystallization of FeSiBNbCu alloys is usually observed after annealing in the range of $500-600{ }^{\circ} \mathrm{C}$ for $1 \mathrm{~h}$ (i.e., at temperatures between the first and second crystallization stages). One of the examples of the evolution of the hysteresis loops of Finemet-type microwires upon nanocrystallization is shown in Figure 23. As can observed from Figure 23, in the case of the $\mathrm{Fe}_{70.8} \mathrm{Cu}_{1} \mathrm{Nb}_{3.1} \mathrm{Si}_{14.5} \mathrm{~B}_{10.6}$ microwire, annealing at $T_{\text {ann }}$ up to $550{ }^{\circ} \mathrm{C}$ allows considerable decrease of coercivity. For these annealing conditions, the character of hysteresis loops does not change: all the hysteresis loops present rectangular shape. In some cases, rectangular hysteresis loops are reported not only upon devitrification of Finemet-type, but even after second crystallization process when values up to $2400 \mathrm{~A} / \mathrm{m}$ are observed [107]. One of the examples is shown in Figure 24a, where hysteresis loop of $\mathrm{Fe}_{71,8} \mathrm{Cu}_{1} \mathrm{Nb}_{3,1} \mathrm{Si}_{15} \mathrm{~B}_{9,1}$ microwire $(\rho=0.282)$ annealed at $T_{\text {ann }}=70{ }^{\circ} \mathrm{C}$ is shown. However, $\mathrm{Fe}_{71,8} \mathrm{Cu}_{1} \mathrm{Nb}_{3,1} \mathrm{Si}_{15} \mathrm{~B}_{9,1}$ microwire $(\rho=0.467)$ present rather different step-wise hysteresis loops (see Figure $24 \mathrm{~b}$ ) that can be attributed to partially crystalline (bi-phase) structure. Such partially crystalline magnetic microwires, with step-wise hysteresis loops related to magnetic interaction between crystals or mixed amorphous-crystalline structure, can be interesting for applications in electronic surveillance systems [108]. 


\section{(a)}
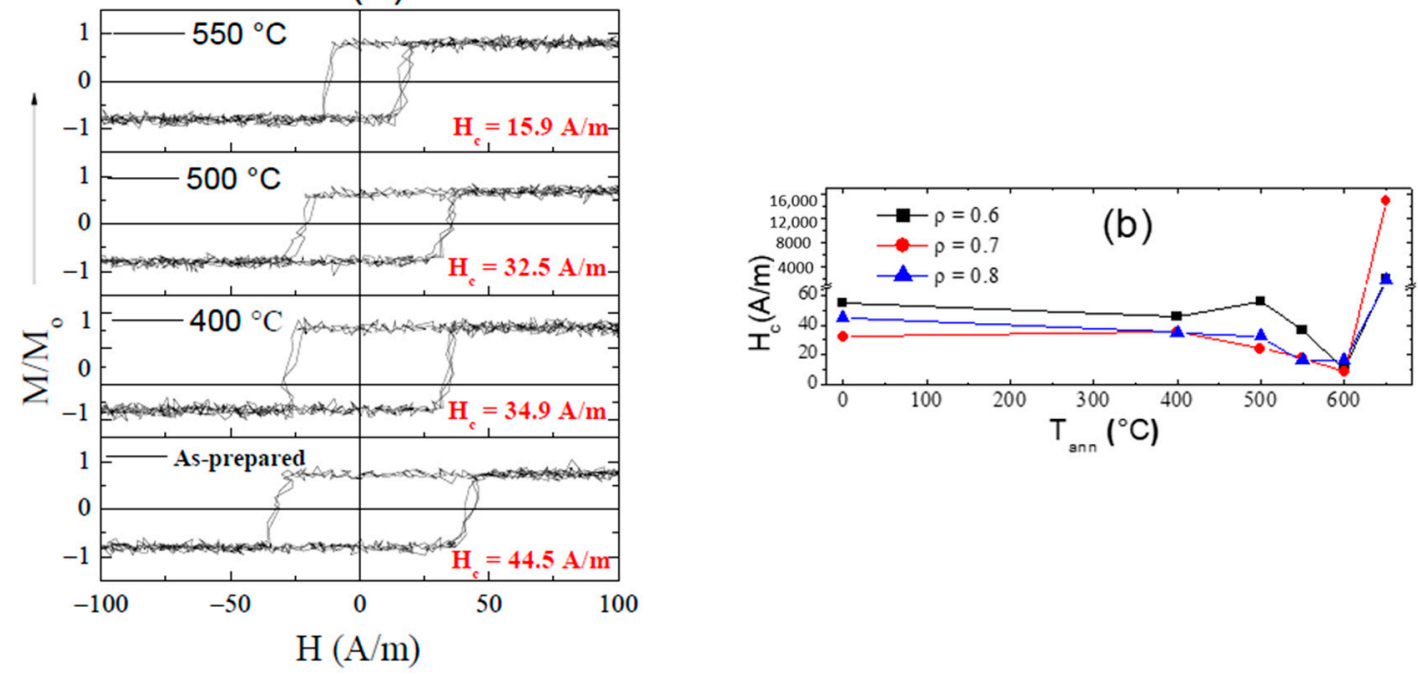

Figure 23. Hysteresis loops of as-prepared and annealed $\mathrm{Fe}_{70.8} \mathrm{Cu}_{1} \mathrm{Nb}_{3.1} \mathrm{Si}_{14.5} \mathrm{~B}_{10.6}$ microwire samples at $T_{\text {ann }}$ between $400-600{ }^{\circ} \mathrm{C}$ (a); coercive field dependence on $\mathrm{T}_{\mathrm{ann}}$ of $\mathrm{Fe}_{70.8} \mathrm{Cu}_{1} \mathrm{Nb}_{3.1} \mathrm{Si}_{14.5} \mathrm{~B}_{10.6}$ for different $\rho$-ratios (b). (Reproduced with permission from [48] Copyright (C) 2016 Springer Nature).

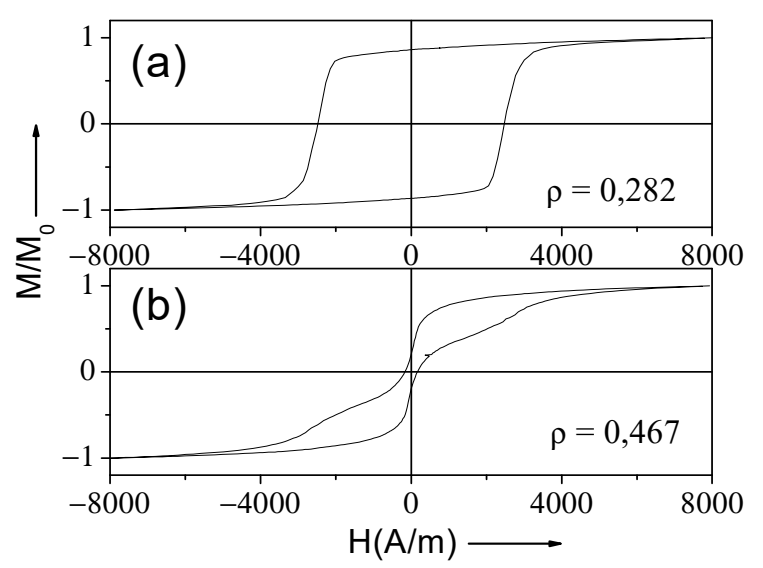

Figure 24. Hysteresis loops of $\mathrm{Fe}_{71,8} \mathrm{Cu}_{1} \mathrm{Nb}_{3,1} \mathrm{Si}_{15} \mathrm{~B}_{9,1}$ microwires with $\rho=0.282$ (a) and $\rho=0.467$ (b) annealed at $700{ }^{\circ} \mathrm{C}$. Adapted from Reference [107].

The microwires obtained by devitrification exhibit higher saturation magnetization and at certain annealing conditions can present better magnetic softness and GMI response than as-prepared Fe-rich microwires and therefore they are useful for GMI sensors and metacomposites applications [47].

In fact, microwires with nanocrystalline structure can be obtained even directly in as-prepared state without annealing $[109,110]$. The advantage of such microwires is that they can present better mechanical properties $[109,110]$.

It is worth mentioning that the use of specially designed compositions allows a further increase of saturation magnetization, $\mu_{0} M_{s}$, [111] and also obtains extremely magnetically soft nanocrystalline materials. In the case of microwires, the use of a similar chemical composition allows preparation of nanocrystalline microwires with improved DW mobility without any post processing [109]. The partially crystalline $\left(\mathrm{Fe}_{0.7} \mathrm{Co}_{0.3}\right)_{83.7} \mathrm{Si}_{4} \mathrm{~B}_{8} \mathrm{P}_{3.6} \mathrm{Cu}_{0.7}$ microwire presents elevated values of $H_{c}$ (about $480 \mathrm{~A} / \mathrm{m}$ ) and rather high saturation magnetization of about 1.6 T (see Figure 25). 


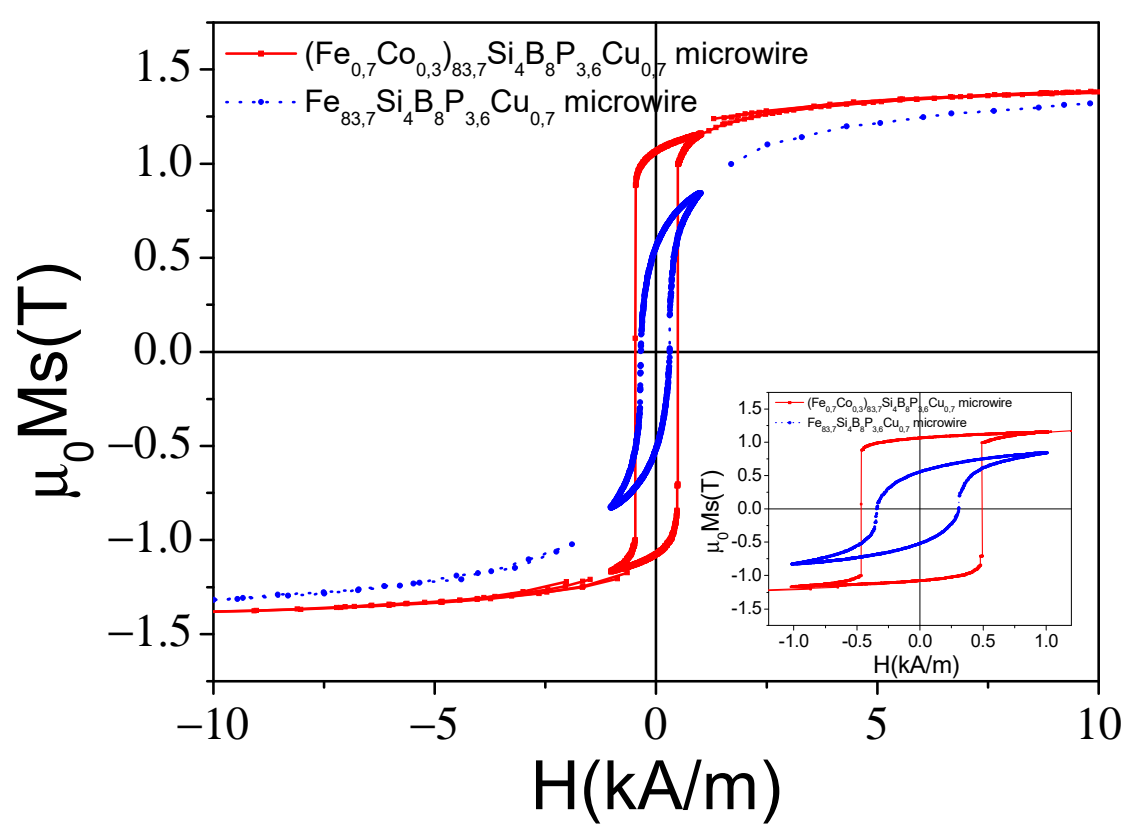

Figure 25. Hysteresis loops of studied $\left(\mathrm{Fe}_{0.7} \mathrm{Co}_{0.3}\right)_{83.7} \mathrm{Si}_{4} \mathrm{~B}_{8} \mathrm{P}_{3.6} \mathrm{Cu}_{0.7}$ and $\mathrm{Fe}_{83.7} \mathrm{Si}_{4} \mathrm{~B}_{8} \mathrm{P}_{3.6} \mathrm{Cu}_{0.7}$ (prepared for comparison) microwires as indicated. (Reproduced with permission from [109] Copyright (C) 2020 Elsevier B.V.)

Such elevated $H_{c}$-values are quite similar to that exhibited by other partially nanocrystalline microwires, i.e., Hitperm-like $\mathrm{Fe}_{38.5} \mathrm{Co}_{38.5} \mathrm{~B}_{18} \mathrm{Mo}_{4} \mathrm{Cu}_{1}$ microwires with similar average grain size (about $38 \mathrm{~nm}$ and $23-33 \mathrm{~nm}$ for $\left(\mathrm{Fe}_{0.7} \mathrm{Co}_{0.3}\right)_{83.7} \mathrm{Si}_{4} \mathrm{~B}_{8} \mathrm{P}_{3.6} \mathrm{Cu}_{0.7}$ and Hitperm-like microwires, respectively) [110]. Accordingly, even partially crystalline or nanocrystalline microwires can present perfectly rectangular hysteresis loops. For a $\left(\mathrm{Fe}_{0.7} \mathrm{Co}_{0.3}\right)_{83.7} \mathrm{Si}_{4} \mathrm{~B}_{8} \mathrm{P}_{3.6} \mathrm{Cu}_{0.7}$ microwire, elevated $\mu_{0} M_{S}$-values allowed for obtaining extremely fast domain wall velocity even in an as-prepared state [110].

Aforementioned Hitperm-like $\mathrm{Fe}_{38.5} \mathrm{Co}_{38.5} \mathrm{~B}_{18} \mathrm{Mo}_{4} \mathrm{Cu}_{1}$ microwires are the other example of nanocrystalline microwires with perfectly rectangular hysteresis loops (see Figure 26) and hence fast magnetization switching by single domain wall propagation [110]. Higher $H_{\mathcal{c}^{-}}$values of $\mathrm{Fe}_{38.5} \mathrm{Co}_{38.5} \mathrm{~B}_{18} \mathrm{Mo}_{4} \mathrm{Cu}_{1}$ and $\left(\mathrm{Fe}_{0.7} \mathrm{Co}_{0.3}\right)_{83.7} \mathrm{Si}_{4} \mathrm{~B}_{8} \mathrm{P}_{3.6} \mathrm{Cu}_{0.7}$ microwires have been attributed to elevated magnetostriction coefficient of these microwires as-compared to Finemet-type microwires.

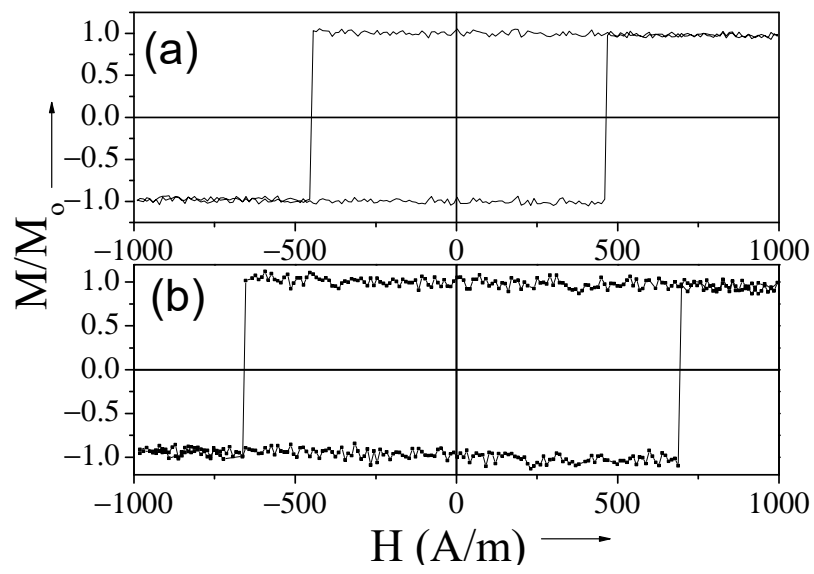

Figure 26. Hysteresis loops of as-prepared $\mathrm{Fe}_{38.5} \mathrm{Co}_{38.5} \mathrm{~B}_{18} \mathrm{Mo}_{4} \mathrm{Cu}_{1}$ microwires: sample 1 with $\rho=0.41$ (a) and sample 2 with $\rho=0.6$ (b) measured at $\mathrm{f}=50 \mathrm{~Hz}$. (Reproduced with permission from [109] Figure 1 Copyright (c) 2016 Elsevier B.V.) 
On the other hand, magnetically hard and semi-hard wires are suitable for some applications specifically to the development of smart markers for the electronic article surveillance, compass needles, motors, tachometers, magnetic microelectromechanical systems (MEMS), magnetic tips for magnetic force microscopy, or dentistry $[112,113]$. Recently, several successful attempts to obtain elevated coercivity in microwires have been reported [114-116]. Among others, various approaches have been developed to increase coercivity through the use of new alloys, i.e., Fe-Pt based alloys [114] or Heusler-type (Ni-Mn-Ga) alloys [115].

Magnetic hardening in $\mathrm{Fe}_{50} \mathrm{Pt}_{40} \mathrm{Si}_{10}$ microwires has been observed after annealing upon the formation of L10-type superstructure after crystallization of as-prepared amorphous precursor (see Figure 27). In this case, after devitrification of amorphous $\mathrm{Fe}_{50} \mathrm{Pt}_{40} \mathrm{Si}_{10}$ microwire, $H_{c} \approx 40 \mathrm{kA} / \mathrm{m}$ is observed.
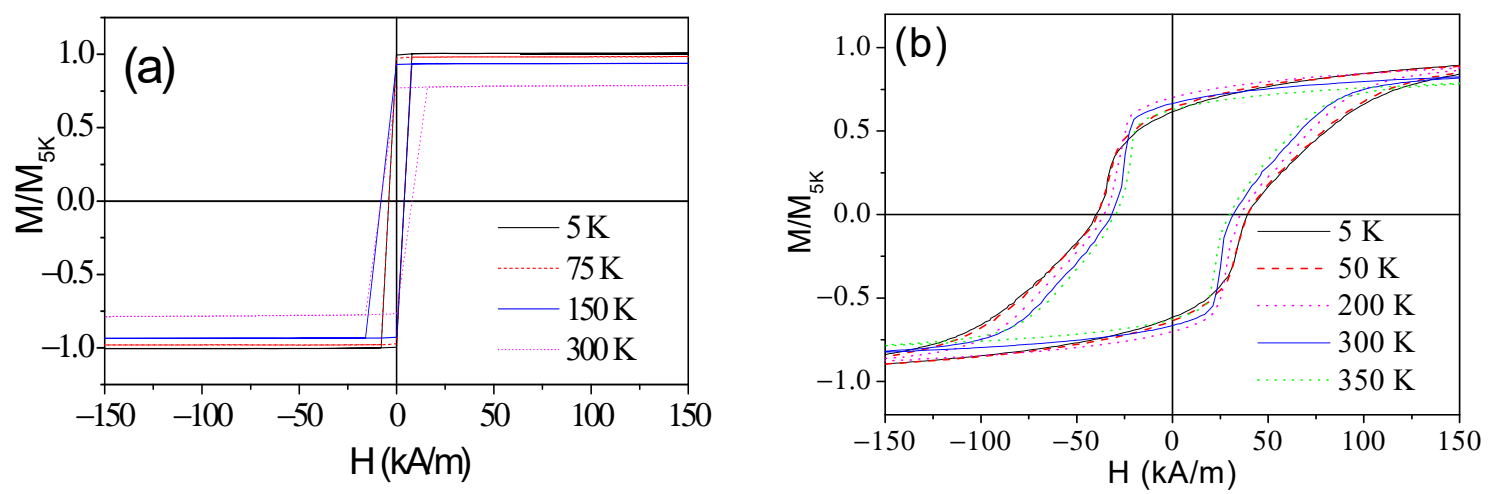

Figure 27. Hysteresis loops of as-prepared (a) and annealed at $500^{\circ} \mathrm{C}$ for $1 \mathrm{~h}$; (b) $\mathrm{Fe}_{50} \mathrm{Pt}_{40} \mathrm{Si}_{10}$ microwires measured at different temperatures. Adapted from Ref. [114].

Magnetic hardening is also reported in Co-rich microwires annealed by Joule heating [116].

Consequently, magnetic properties of crystalline microwires depend on the chemical composition of the metallic nucleus and on structural features (grain size, precipitating phases) of either as-prepared or annealed microwire: crystalline microwire can exhibit either soft magnetic properties or semi-hard magnetic properties.

\section{Conclusions}

We showed that the magnetic properties of glass-coated microwires prepared by the Taylor-Ulitovsky method can be tuned in an as-prepared state or further modified by appropriate post-processing.

Magnetic properties of amorphous magnetic microwires can be tuned either in as-prepared state or by controlling the magnetoelastic anisotropy through the magnetostriction coefficient value and by the internal stresses values related to the fabrication conditions and geometry of microwires. Furthermore, appropriate post-processing (including either conventional heat treatment, heat treatment in the presence of applied stress or magnetic field, or glass-coating removal) allows further tuning of magnetic properties of magnetic microwires.

We showed that the microwires with coercivities from $1 \mathrm{~A} / \mathrm{m}$ to $40 \mathrm{kA} / \mathrm{m}$ can be prepared.

Depending on the chemical composition of metallic nucleus as well as structural features (grain size, precipitating phases), a prepared microwire can exhibit soft magnetic properties or semi-hard magnetic properties.

Author Contributions: Conceptualization, A.Z. and V.Z.; methodology, M.I., J.M.B., and V.Z.; validation, A.Z.; formal analysis, A.Z.; investigation, A.Z., A.T., P.C.-L., J.O., L.G.-L., and V.Z.; resources, A.Z.; data curation, V.Z., P.C.-L., J.M.B., M.I., L.G.-L., and A.T.; writing-original draft preparation, A.Z.; writing-review and editing, A.Z., P.C.-L., J.M.B., L.G.-L., and A.T.; supervision, A.Z.; funding acquisition, A.Z. and V.Z. All authors have read and agreed to the published version of the manuscript. 
Funding: This research was funded by Spanish MCIU under PGC2018-099530-B-C31 (MCIU/AEI/FEDER, UE), by the Government of the Basque Country under PIBA 2018-44 and Elkartek (CEMAP and AVANSITE) projects and by the University of Basque Country under the scheme of “Ayuda a Grupos Consolidados" (Ref.: GIU18/192).

Acknowledgments: The authors are thankful for technical and human support to SGIker of UPV/EHU (Medidas Magnéticas Gipuzcoa) and European funding (ERDF and ESF).

Conflicts of Interest: The authors declare no conflict of interest.

\section{References}

1. Lenz, J.; Edelstein, S. Magnetic sensors and their applications. IEEE Sens. J. 2006, 6, 631-649. [CrossRef]

2. Díaz-Michelena, M. Small Magnetic Sensors for Space Applications. Sensors 2009, 9, 2271-2288. [CrossRef] [PubMed]

3. Ripka, P.; Vértesy, G. Sensors based on soft magnetic materials Panel discussion. J. Magn. Magn. Mater. 2000, 215, 795-799. [CrossRef]

4. Fiorillo, F.; Bertotti, G.; Appino, C.; Pasquale, M. Soft Magnetic Materials. In Wiley Encyclopedia of Electrical and Electronics Engineering; John Wiley \& Sons, Inc.: Hoboken, NJ, USA, 2016; pp. 1-42.

5. Jiles, D.C. Recent advances and future directions in magnetic materials. Acta Mater. 2003, 51, 5907-5939. [CrossRef]

6. Zhukov, A. (Ed.) High Performance Soft Magnetic Materials; Springer Series in Materials Science; Springer International Publishing: Cham, Switzerland, 2017; p. 216. ISBN 978-3-319-49705-1.

7. Mohri, K.; Humphrey, F.B.; Kawashima, K.; Kimura, K.; Mizutani, M. Large Barkhausen and Matteucci effects in $\mathrm{FeCoSiB}, \mathrm{FeCrSiB}$, and FeNiSiB amorphous wires. IEEE Trans. Magn. 1990, 26, 1789-1791. [CrossRef]

8. Ogasawara, I.; Ueno, S. Preparation and properties of amorphous wires. IEEE Trans. Magn. 1995, 31, 1219-1223. [CrossRef]

9. Vazquez, M.; Chen, D.-X. The magnetization reversal process in amorphous wires. IEEE Trans. Magn. 1995, 31, 1229-1238. [CrossRef]

10. Panina, L.V.; Mohri, K. Magneto-impedance effect in amorphous wires. Appl. Phys. Lett. 1994, 65, 1189-1191. [CrossRef]

11. Beach, R.S.; Berkowitz, A.E. Giant magnetic field dependent impedance of amorphous FeCoSiB wire. Appl. Phys. Lett. 1994, 64, 3652-3654. [CrossRef]

12. Zhukov, A.; Ipatov, M.; Zhukova, V. Chapter 2-Advances in Giant Magnetoimpedance of Materials. In Handbook of Magnetic Materials; Buschow, K.H.J., Ed.; Elsevier: Amsterdam, The Netherlands, 2015; Volume 24, pp. 139-236.

13. Knobel, M.; Vázquez, M.; Kraus, L. Giant Magnetoimpedance. In Handbook of Magnetic Materials; Elsevier: Amsterdam, The Netherlands, 2003; Volume 15, pp. 497-563.

14. Harrison, E.P.; Turney, G.L.; Rowe, H. Electrical Properties of Wires of High Permeability. Nature 1935, 135, 961. [CrossRef]

15. Sixtus, K.J.; Tonks, L. Propagation of Large Barkhausen Discontinuities. II. Phys. Rev. 1932, 42, $419-435$. [CrossRef]

16. Zhukov, A.P. The remagnetization process of bistable amorphous alloys. Mater. Des. 1993, 14, $299-306$. [CrossRef]

17. Phan, M.-H.; Peng, H.-X.; Yu, S.-C.; Vázquez, M. Optimized giant magnetoimpedance effect in amorphous and nanocrystalline materials. J. Appl. Phys. 2006, 99, 08C505. [CrossRef]

18. Zhukov, A.; Zhukova, V.; Blanco, J.M.; Gonzalez, J. Recent research on magnetic properties of glass-coated microwires. J. Magn. Magn. Mater. 2005, 294, 182-192. [CrossRef]

19. Varga, R.; Richter, K.; Zhukov, A.; Larin, V. Domain Wall Propagation in Thin Magnetic Wires. IEEE Trans. Magn. 2008, 44, 3925-3930. [CrossRef]

20. Corodeanu, S.; Chiriac, H.; Óvári, T.-A. Accurate measurement of domain wall velocity in amorphous microwires, submicron wires, and nanowires. Rev. Sci. Instrum. 2011, 82, 094701. [CrossRef]

21. Biziere, N.; Gatel, C.; Lassalle-Balier, R.; Clochard, M.C.; Wegrowe, J.E.; Snoeck, E. Imaging the Fine Structure of a Magnetic Domain Wall in a Ni Nanocylinder. Nano Lett. 2013, 13, 2053-2057. [CrossRef] 
22. Da Col, S.; Jamet, S.; Staňo, M.; Trapp, B.; Le Denmat, S.; Cagnon, L.; Toussaint, J.C.; Fruchart, O. Nucleation, imaging, and motion of magnetic domain walls in cylindrical nanowires. Appl. Phys. Lett. 2016, 109, 062406. [CrossRef]

23. Blanco, J.M.; Zhukova, V.; Ipatov, M.; Zhukov, A. Magnetic Properties and Domain Wall Propagation in Micrometric Amorphous Microwires. Sens. Lett. 2013, 11, 187-190. [CrossRef]

24. Óvári, T.-A.; Corodeanu, S.; Chiriac, H. Domain wall velocity in submicron amorphous wires. J. Appl. Phys. 2011, 109, 07D502. [CrossRef]

25. Pirota, K.R.; Kraus, L.; Chiriac, H.; Knobel, M. Magnetic properties and giant magnetoimpedance in a CoFeSiB glass-covered microwire. J. Magn. Magn. Mater. 2000, 221, L243-L247. [CrossRef]

26. Corte-León, P.; Zhukova, V.; Ipatov, M.; Blanco, J.M.; Gonzalez, J.; Zhukov, A. Engineering of magnetic properties of Co-rich microwires by joule heating. Intermetallics 2019, 105, 92-98. [CrossRef]

27. Mohri, K.; Uchiyama, T.; Panina, L.V.; Yamamoto, M.; Bushida, K. Recent Advances of Amorphous Wire CMOS IC Magneto-Impedance Sensors: Innovative High-Performance Micromagnetic Sensor Chip. Available online: https://www.hindawi.com/journals/js/2015/718069/abs/ (accessed on 18 January 2019).

28. Honkura, Y.; Honkura, S. The Development of ASIC Type GSR Sensor Driven by GHz Pulse Current. Sensors 2020, 20, 1023. [CrossRef] [PubMed]

29. Sandacci, S.; Makhnovskiy, D.; Panina, L.; Mohri, K.; Honkura, Y. Off-diagonal impedance in amorphous wires and its application to linear magnetic sensors. IEEE Trans. Magn. 2004, 40, 3505-3511. [CrossRef]

30. Dufay, B.; Saez, S.; Dolabdjian, C.; Yelon, A.; Menard, D. Development of a High Sensitivity Giant Magneto-Impedance Magnetometer: Comparison with a Commercial Flux-Gate. IEEE Trans. Magn. 2013, 49, 85-88. [CrossRef]

31. Uchiyama, T.; Mohri, K.; Nakayama, S. Measurement of Spontaneous Oscillatory Magnetic Field of Guinea-Pig Smooth Muscle Preparation Using Pico-Tesla Resolution Amorphous Wire Magneto-Impedance Sensor. IEEE Trans. Magn. 2011, 47, 3070-3073. [CrossRef]

32. Cobeño, A.F.; Zhukov, A.; Blanco, J.M.; Larin, V.; Gonzalez, J. Magnetoelastic sensor based on GMI of amorphous microwire. Sens. Actuators Phys. 2001, 91, 95-98. [CrossRef]

33. Zhukova, V.; Blanco, J.M.; Ipatov, M.; Zhukov, A.; García, C.; Gonzalez, J.; Varga, R.; Torcunov, A. Development of thin microwires with low Curie temperature for temperature sensors applications. Sens. Actuators B Chem. 2007, 126, 318-323. [CrossRef]

34. Ulitovsky, A.V.; Maianski, I.M.; Avramenco, A.I. Method of Continuous Casting of Glass Coated Microwire. USSR Patent No. 128427, 15 May 1960. Bulletin 1960, 10, 14.

35. Kraus, L.; Schneider, J.; Wiesner, H. Ferromagnetic resonance in amorphous alloys prepared by rapid quenching from the melt. Czech. J. Phys. B 1976, 26, 601-602. [CrossRef]

36. Zhukov, A.; Ipatov, M.; Talaat, A.; Blanco, J.M.; Hernando, B.; Gonzalez-Legarreta, L.; Suñol, J.J.; Zhukova, V. Correlation of Crystalline Structure with Magnetic and Transport Properties of Glass-Coated Microwires. Crystals 2017, 7, 41. [CrossRef]

37. Baranov, S.A.; Larin, V.S.; Torcunov, A.V. Technology, Preparation and Properties of the Cast Glass-Coated Magnetic Microwires. Crystals 2017, 7, 136. [CrossRef]

38. Zhukova, V.; Blanco, J.M.; Ipatov, M.; Zhukov, A. Magnetoelastic Contribution in Domain-Wall Dynamics of Magnetically Bistable Microwires. IEEE Trans. Magn. 2011, 47, 3783-3787. [CrossRef]

39. Zhukov, A.; Gonzalez, J.; Zhukova, V. Magnetoresistance in thin wires with granular structure. J. Magn. Magn. Mater. 2005, 294, 165-173. [CrossRef]

40. Zhukov, A.; Rodionova, V.; Ilyn, M.; Aliev, A.M.; Varga, R.; Michalik, S.; Aronin, A.; Abrosimova, G.; Kiselev, A.; Ipatov, M.; et al. Magnetic properties and magnetocaloric effect in Heusler-type glass-coated NiMnGa microwires. J. Alloys Compd. 2013, 575, 73-79. [CrossRef]

41. Zhukova, V.; Talaat, A.; del Val, J.J.; Ipatov, M.; Zhukov, A. Preparation and Characterization of Fe-Pt and Fe-Pt-(B, Si) Microwires. IEEE Magn. Lett. 2016, 7, 5200704. [CrossRef]

42. Zhukova, V.; Corte-Leon, P.; Ipatov, M.; Blanco, J.M.; Gonzalez-Legarreta, L.; Zhukov, A. Development of Magnetic Microwires for Magnetic Sensor Applications. Sensors 2019, 19, 4767. [CrossRef]

43. Zhukov, A.; Ipatov, M.; Corte-León, P.; Gonzalez-Legarreta, L.; Blanco, J.M.; Zhukova, V. Soft magnetic microwires for sensor applications. J. Magn. Magn. Mater. 2020, 498, 166180. [CrossRef]

44. Antonov, A.S.; Borisov, V.T.; Borisov, O.V.; Prokoshin, A.F.; Usov, N.A. Residual quenching stresses in glass-coated amorphous ferromagnetic microwires. J. Phys. Appl. Phys. 2000, 33, 1161. [CrossRef] 
45. Zhukova, V.; Blanco, J.M.; Ipatov, M.; Zhukov, A. Magnetoelastic contribution in domain wall dynamics of amorphous microwires. Phys. B Condens. Matter 2012, 407, 1450-1454. [CrossRef]

46. Zhukov, A.; Cobeño, A.F.; Gonzalez, J.; Torcunov, A.; Pina, E.; Prieto, M.J.; Blanco, J.M.; Larin, V.; Baranov, S. Ferromagnetic resonance, magnetic behaviour and structure of Fe-based glass-coated microwires. J. Magn. Magn. Mater. 1999, 203, 238-240. [CrossRef]

47. Velázquez, J.; Vázquez, M.; Hernando, A.; Savage, H.T.; Wun-Fogle, M. Magnetoelastic anisotropy in amorphous wires due to quenching. J. Appl. Phys. 1991, 70, 6525-6527. [CrossRef]

48. Talaat, A.; Zhukova, V.; Ipatov, M.; del Val, J.J.; Blanco, J.M.; Gonzalez-Legarreta, L.; Hernando, B.; Churyukanova, M.; Zhukov, A. Engineering of Magnetic Softness and Magnetoimpedance in Fe-Rich Microwires by Nanocrystallization. JOM 2016, 68, 1563-1571. [CrossRef]

49. Gonzalez-Legarreta, L.; Corte-León, P.; Zhukova, V.; Ipatov, M.; Blanco, J.M.; Churyukanova, M.; Taskaev, S.; Zhukov, A. Route of magnetoimpedance and domain walls dynamics optimization in Co-based microwires. J. Alloys Compd. 2020, 830, 154576. [CrossRef]

50. Goto, T.; Nagano, M.; Wehara, N. Mechanical Properties of Amorphous Fe80P16C3B1 Filament Produced by Glass-Coated Melt Spinning. Trans. Jpn. Inst. Met. 1977, 18, 759-764. [CrossRef]

51. Zhukova, V.; Cobeño, A.F.; Zhukov, A.; de Arellano Lopez, A.R.; Blanco, J.M.; Larin, V.; Gonzalez, J.; López-Pombero, S. Correlation between magnetic and mechanical properties of devitrified glass-coated Fe71.8Cu1Nb3.1Si15B9.1 microwires. J. Magn. Magn. Mater. 2002, 249, 79-84. [CrossRef]

52. Corte-León, P.; Gonzalez-Legarreta, L.; Zhukova, V.; Ipatov, M.; Blanco, J.M.; Churyukanova, M.; Taskaev, S.; Zhukov, A. Controlling the domain wall dynamics in Fe-, Ni- and Co-based magnetic microwires. J. Alloys Compd. 2020, 834, 155170. [CrossRef]

53. Zhukov, A.; Talaat, A.; Ipatov, M.; Zhukova, V. Tailoring the High-Frequency Giant Magnetoimpedance Effect of Amorphous Co-Rich Microwires. IEEE Magn. Lett. 2015, 6, 1-4. [CrossRef]

54. Zhukov, A.; Churyukanova, M.; Kaloshkin, S.; Sudarchikova, V.; Gudoshnikov, S.; Ipatov, M.; Talaat, A.; Blanco, J.M.; Zhukova, V. Magnetostriction of Co-Fe-Based Amorphous Soft Magnetic Microwires. J. Electron. Mater. 2016, 45, 226-234. [CrossRef]

55. Churyukanova, M.; Semenkova, V.; Kaloshkin, S.; Shuvaeva, E.; Gudoshnikov, S.; Zhukova, V.; Shchetinin, I.; Zhukov, A. Magnetostriction investigation of soft magnetic microwires. Phys. Status Solidi A 2016, 213,363-367. [CrossRef]

56. Konno, Y.; Mohri, K. Magnetostriction measurements for amorphous wires. IEEE Trans. Magn. 1989, 25, 3623-3625. [CrossRef]

57. Herzer, G. Amorphous and nanocrystalline soft magnets. In Magnetic Hysteresis in Novel Magnetic Materials; NATO ASI Series (Series E: Applied Sciences); Hadjipanayis, G.C., Ed.; Kluwer Academic Publishers: Dordrecht, The Netherlands, 1997; Volume 338, pp. 711-730.

58. Cobeño, A.F.; Zhukov, A.; Blanco, J.M.; Gonzalez, J. Giant magneto-impedance effect in CoMnSiB amorphous microwires. J. Magn. Magn. Mater. 2001, 234, L359-L365. [CrossRef]

59. Corte-Leon, P.; Zhukova, V.; Blanco, J.M.; González-Legarreta, L.; Ipatov, M.; Zhukov, A. Stress-induced Magnetic Anisotropy Enabling Engineering of Magnetic Softness of Fe-rich Amorphous Microwires. J. Magn. Magn. Mater. 2020, 510, 166939. [CrossRef]

60. Zhukova, V.; Blanco, J.M.; Chizhik, A.; Ipatov, M.; Zhukov, A. AC-current-induced magnetization switching in amorphous microwires. Front. Phys. 2018, 13, 137501. [CrossRef]

61. Zhukova, V.; Zhukov, A.; Blanco, J.M.; Gonzalez, J.; Ponomarev, B.K. Switching field fluctuations in a glass-coated Fe-rich amorphous microwire. J. Magn. Magn. Mater. 2002, 249, 131-135. [CrossRef]

62. Chiriac, H.; Óvári, T.-A.; Corodeanu, S.; Ababei, G. Interdomain wall in amorphous glass-coated microwires. Phys. Rev. B 2007, 76, 214433. [CrossRef]

63. Astefanoaei, I.; Radu, D.; Chiriac, H. Internal stress distribution in DC joule-heated amorphous glass-covered microwires. J. Phys. Condens. Matter 2006, 18, 2689-2716. [CrossRef]

64. Chiriac, H.; Óvári, T.A.; Pop, G. Internal stress distribution in glass-covered amorphous magnetic wires. Phys. Rev. B 1995, 52, 10104-10113. [CrossRef]

65. García-Prieto, M.J.; Pina, E.; Zhukov, A.; Larin, V.; Marín, P.; Vázquez, M.; Hernando, A. Glass-coated Co-rich amorphous microwires with enhanced permeability. Sens. Actuators A Phys. 2000, 81, 227-231. [CrossRef] 
66. Catalan, C.F.; Prida, V.M.; Alonso, J.; Vázquez, M.; Zhukov, A.; Hernando, B.; Velázquez, J. Effect of glass coating on magnetic properties of amorphous microwires, Rapidly Quenched \& Metastable Materials. Mater. Sci. Eng. A Suppl. 1997, 438-441.

67. Takajo, M.; Yamasaki, J.; Humphrey, F.B. Domain structure of chemically thinned Fe-Si-B amorphous wires. IEEE Trans. Magn. 1999, 35, 3904-3906. [CrossRef]

68. Kabanov, Y.; Zhukov, A.; Zhukova, V.; Gonzalez, J. Magnetic domain structure of wires studied by using the magneto-optical indicator film method. Appl. Phys. Lett. 2005, 87, 142507. [CrossRef]

69. Usov, N.; Antonov, A.; Dykhne, A.; Lagar'kov, A. Possible origin for the bamboo domain structure in Co-rich amorphous wire. J. Magn. Magn. Mater. 1997, 174, 127-132. [CrossRef]

70. Nderu, J.N.; Takajo, M.; Yamasaki, J.; Humphrey, F.B. Effect of stress on the bamboo domains and magnetization process of CoSiB amorphous wire. IEEE Trans. Magn. 1998, 34, 1312-1314. [CrossRef]

71. Corte-Leon, P.; Zhukova, V.; Ipatov, M.; Blanco, J.M.; Gonzalez, J.; Churyukanova, M.; Baraibar, J.M.; Taskaev, S.; Zhukov, A. Stress dependence of the magnetic properties of glass-coated amorphous microwires. J. Alloys Compd. 2019, 789, 201-208. [CrossRef]

72. Barandiarán, J.M.; Hernando, A.; Madurga, V.; Nielsen, O.V.; Vázquez, M.; Vázquez-López, M. Temperature, stress, and structural-relaxation dependence of the magnetostriction in $\left(\mathrm{Co}_{0.94} \mathrm{Fe}_{0.06}\right)_{75} \mathrm{Si}_{15} \mathrm{~B}_{10}$ glasses. Phys. Rev. B 1987, 35, 5066-5071. [CrossRef]

73. Zhukov, A.; Ipatov, M.; Gonzalez, J.; Blanco, J.M.; Zhukova, V. Recent advances in studies of magnetically soft amorphous microwires. J. Magn. Magn. Mater. 2009, 321, 822-825. [CrossRef]

74. Zhukov, A.; Ipatov, M.; Corte-León, P.; Legarreta, L.G.; Churyukanova, M.; Blanco, J.M.; Gonzalez, J.; Taskaev, S.; Hernando, B.; Zhukova, V. Giant magnetoimpedance in rapidly quenched materials. J. Alloys Compd. 2020, 814, 152225. [CrossRef]

75. Zhukov, A.; González, J.; Blanco, J.M.; Vázquez, M.; Larin, V. Microwires coated by glass: A new family of soft and hard magnetic materials. J. Mater. Res. 2000, 15, 2107-2113. [CrossRef]

76. Allwood, D.A.; Xiong, G.; Faulkner, C.C.; Atkinson, D.; Petit, D.; Cowburn, R.P. Magnetic Domain-Wall Logic. Science 2005, 309, 1688-1692. [CrossRef]

77. Moriya, R.; Hayashi, M.; Thomas, L.; Rettner, C.; Parkin, S.S.P. Dependence of field driven domain wall velocity on cross-sectional area in $\mathrm{Ni}_{65} \mathrm{Fe}_{20} \mathrm{Co}_{15}$ nanowires. Appl. Phys. Lett. 2010, 97, 142506. [CrossRef]

78. Zhukova, V.; Blanco, J.M.; Rodionova, V.; Ipatov, M.; Zhukov, A. Domain wall propagation in micrometric wires: Limits of single domain wall regime. J. Appl. Phys. 2012, 111, 07E311. [CrossRef]

79. Zhukova, V.; Blanco, J.M.; Rodionova, V.; Ipatov, M.; Zhukov, A. Fast magnetization switching in Fe-rich amorphous microwires: Effect of magnetoelastic anisotropy and role of defects. J. Alloys Compd. 2014, 586, S287-S290. [CrossRef]

80. Aragoneses, P.; Blanco, J.M.; Dominguez, L.; González, J.; Zhukov, A.; Vázquez, M. The Stress dependence of the switching field in glass-coated amorphous microwires. J. Phys. D Appl. Phys. 1998, 31, 3040-3045. [CrossRef]

81. Zhukova, V.; Talaat, A.; Corte-Leon, P.; Blanco, J.M.; Ipatov, M.; Zhukov, A. Engineering of magnetic properties and domain wall dynamics in Fe-Ni-based amorphous microwires by annealing. Aip Adv. 2020, 10, 015130. [CrossRef]

82. Zhukov, A.; Churyukanova, M.; Kaloshkin, S.; Semenkova, V.; Gudoshnikov, S.; Ipatov, M.; Talaat, A.; Blanco, J.M.; Zhukova, V. Effect of annealing on magnetic properties and magnetostriction coefficient of Fe-Ni-based amorphous microwires. J. Alloys Compd. 2015, 651, 718-723. [CrossRef]

83. Luborsky, F.; Walter, J. Magnetic anneal anisotropy in amorphous alloys. IEEE Trans. Magn. 1977, 13, $953-956$. [CrossRef]

84. Haimovich, J.; Jagielinski, T.; Egami, T. Magnetic and structural effects of anelastic deformation of an amorphous alloy. J. Appl. Phys. 1985, 57, 3581-3583. [CrossRef]

85. Zhukova, V.; Korchuganova, O.A.; Aleev, A.A.; Tcherdyntsev, V.V.; Churyukanova, M.; Medvedeva, E.V.; Seils, S.; Wagner, J.; Ipatov, M.; Blanco, J.M.; et al. Effect of annealing on magnetic properties and structure of Fe-Ni based magnetic microwires. J. Magn. Magn. Mater. 2017, 433, 278-284. [CrossRef]

86. Zhukova, V.; Blanco, J.M.; Ipatov, M.; Gonzalez, J.; Churyukanova, M.; Zhukov, A. Engineering of magnetic softness and giant magnetoimpedance effect in Fe-rich microwires by stress-annealing. Scr. Mater. 2018, 142, 10-14. [CrossRef] 
87. Zhukova, V.; Blanco, J.M.; Ipatov, M.; Churyukanova, M.; Taskaev, S.; Zhukov, A. Tailoring of magnetoimpedance effect and magnetic softness of Fe-rich glass-coated microwires by stress- annealing. Sci. Rep. 2018, 8, 1-14. [CrossRef] [PubMed]

88. Yamasaki, J.; Mohri, K.; Watari, K.; Narita, K. Domain wall induced anisotropy during annealing in amorphous ribbons. IEEE Trans. Magn. 1984, 20, 1855-1857. [CrossRef]

89. Kohmoto, O.; Ohya, K. Amorphous FeCo-SiB alloys with zero magnetostriction. J. Appl. Phys. 1981, 52, 928-932. [CrossRef]

90. Becker, J.; Luborsky, F.; Walter, J. Magnetic moments and Curie temperatures of $(\mathrm{Fe}, \mathrm{Ni})_{80}(\mathrm{P}, \mathrm{B})_{20}$ amorphous alloys. IEEE Trans. Magn. 1977, 13, 988-991. [CrossRef]

91. Rancourt, D.G.; Dang, M.-Z. Relation between anomalous magnetovolume behavior and magnetic frustration in Invar alloys. Phys. Rev. B 1996, 54, 12225-12231. [CrossRef]

92. Gaskell, P.H. On the structure of simple inorganic amorphous solids. J. Phys. C Solid State Phys. 1979, 12, 4337-4368. [CrossRef]

93. Zhukov, A.; Chichay, K.; Talaat, A.; Rodionova, V.; Blanco, J.M.; Ipatov, M.; Zhukova, V. Manipulation of magnetic properties of glass-coated microwires by annealing. J. Magn. Magn. Mater. 2015, 383, 232-236. [CrossRef]

94. Zhukov, A.; Talaat, A.; Churyukanova, M.; Kaloshkin, S.; Semenkova, V.; Ipatov, M.; Blanco, J.M.; Zhukova, V. Engineering of magnetic properties and GMI effect in Co-rich amorphous microwires. J. Alloys Compd. 2016, 664, 235-241. [CrossRef]

95. Corte-León, P.; Talaat, A.; Zhukova, V.; Ipatov, M.; Blanco, J.M.; Gonzalez, J.; Zhukov, A. Stress-Induced Magnetic Anisotropy Enabling Engineering of Magnetic Softness and GMI Effect of Amorphous Microwires. Appl. Sci. 2020, 10, 981. [CrossRef]

96. Zhukov, A.; Talaat, A.; Blanco, J.M.; Ipatov, M.; Zhukova, V. Tuning of Magnetic Properties and GMI Effect of Co-Based Amorphous Microwires by Annealing. J. Electron. Mater. 2014, 43, 4532-4539. [CrossRef]

97. Aragoneses, P.; Blanco, J.M.; Cobeño, A.F.; Dominguez, L.; Gonzalez, J.; Zhukov, A.; Larin, V. Stress Dependence of the Switching Field in Co-rich Amorphous Microwires. J. Magn. Magn. Mater. 1999, 196, 248-250. [CrossRef]

98. Corte-León, P.; Blanco, J.M.; Zhukova, V.; Ipatov, M.; Gonzalez, J.; Churyukanova, M.; Taskaev, S.; Zhukov, A. Engineering of Magnetic Softness and Domain Wall Dynamics of Fe-rich Amorphous Microwires by Stress-induced Magnetic Anisotropy. Sci. Rep. 2019, 9, 1-14. [CrossRef] [PubMed]

99. Larin, V.S.; Zhukova, V.; Zhukov, A.; Torcunov, A.V.; Vazquez, M. Tailoring of magnetic anisotropy in Fe-rich glass-coated magnetic microwires by thermo-mechanical annealing. Sens. Actuators A Phys. 2003, 106, 96-100. [CrossRef]

100. Zhukov, A.; Zhukova, V.; Larin, V.; Gonzalez, J. Tailoring of magnetic anisotropy of Fe-rich microwires by stress induced anisotropy. Phys. B Condens. Matter 2006, 384,1-4. [CrossRef]

101. Gonzalez-Legarreta, L.; Corte-Leon, P.; Zhukova, V.; Ipatov, M.; Blanco, J.M.; Gonzalez, J.; Zhukov, A. Optimization of magnetic properties and GMI effect of Thin Co-rich Microwires for GMI Microsensors. Sensors 2020, 20, 1558. [CrossRef]

102. Chichay, K.; Rodionova, V.; Ipatov, M.; Zhukova, V.; Zhukov, A. Effect of Temperature and Time of Stress Annealing on Magnetic Properties of Amorphous Microwires. Acta Phys. Pol. A 2015, 127, 600-602. [CrossRef]

103. Corte-León, P.; Zhukova, V.; Ipatov, M.; Blanco, J.M.; González, J.; Zhukov, A. Optimization of GMI Effect and Magnetic Properties of Co-Rich Microwires by Joule Heating. IEEE Trans. Magn. 2019, 55, 1-4. [CrossRef]

104. Zhukova, V.; Cobeño, A.F.; Zhukov, A.; Blanco, J.M.; Puerta, S.; Gonzalez, J.; Vázquez, M. Tailoring of magnetic properties of glass-coated microwires by current annealing. J. Non-Cryst. Solids 2001, 287, 31-36. [CrossRef]

105. Becker, J. A new mechanism for magnetic annealing in amorphous metals. IEEE Trans. Magn. 1978, 14, 938-940. [CrossRef]

106. Zhukov, A.P.; Talaat, A.; Ipatov, M.; Blanco, J.M.; Gonzalez-Legarreta, L.; Hernando, B.; Zhukova, V. Effect of Nanocrystallization on Magnetic Properties and GMI Effect of Microwires. IEEE Trans. Magn. 2014, 50, 1-5. [CrossRef]

107. Zhukova, V.; Cobeño, A.F.; Zhukov, A.; Blanco, J.M.; Larin, V.; Gonzalez, J. Coercivity of glass-coated $\mathrm{Fe}_{73.4-\mathrm{x}} \mathrm{Cu}_{1} \mathrm{Nb}_{3.1} \mathrm{Si}_{13.4+\mathrm{x}} \mathrm{B}_{9.1}(0 \leq \mathrm{x} \leq 1.6)$ microwires. Nanostruct. Mater. 1999, 11, 1319-1327. [CrossRef] 
108. Rodionova, V.; Ipatov, M.; Ilyn, M.; Zhukova, V.; Perov, N.; Gonzalez, J.; Zhukov, A. Tailoring of Magnetic Properties of Magnetostatically-Coupled Glass-Covered Magnetic Microwires. J. Supercond. Nov. Magn. 2011, 24, 541-547. [CrossRef]

109. Zhukova, V.; Ipatov, M.; Corte-Leon, P.; Blanco, J.M.; Zanaeva, E.; Bazlov, A.I.; Jiang, J.; Louzguine-Luzgin, D.V.; Olivera, J.; Zhukov, A. Excellent magnetic properties of $\left(\mathrm{Fe}_{0.7} \mathrm{Co}_{0.3}\right)_{83.7} \mathrm{Si}_{4} \mathrm{~B}_{8} \mathrm{P}_{3.6} \mathrm{Cu}_{0.7}$ ribbons and microwires. Intermetallics 2020, 117, 106660. [CrossRef]

110. Talaat, A.; Del Val, J.J.; Zhukova, V.; Ipatov, M.; Klein, P.; Varga, R.; Gonzalez, J.; Zhdanova, M.; Churyukanova, M.; Zhukov, A. Effect of annealing on magnetic properties of nanocrystalline Hitperm-type glass-coated microwires. J. Alloys Compd. 2016, 660, 297-303. [CrossRef]

111. Zhang, Y.; Sharma, P.; Makino, A. Effects of minor precipitation of large size crystals on magnetic properties of Fe-Co-Si-B-P-Cu alloy. J. Alloys Compd. 2017, 709, 663-667. [CrossRef]

112. Cordery, R.A.; Murphy, C.F.M., III. Deactivatable Electronic Article Surveillance Markers Using Short Semi-Hard Magnetic Wires. U.S. Patent 5,191,315, 2 March 1993.

113. Ferri, A.F.A.; Pereira-da-Silva, M.A.; Marega, E., Jr. Magnetic Force Microscopy: Basic Principles and Applications, Atomic Force Microscopy-Imaging, Measuring and Manipulating Surfaces at the Atomic Scale; Bellitto, V., Ed.; InTech: Rijeka, Croatia, 2012.

114. Zhukov, A.; Ipatov, M.; Talaat, A.; Aronin, A.; Abrosimova, G.; del Val, J.J.; Zhukova, V. Magnetic hardening of Fe-Pt and Fe-Pt-M (M=B, Si) microwires. J. Alloys Compd. 2018, 735, 1071-1078. [CrossRef]

115. Zhukov, A.; Ipatov, M.; del Val, J.J.; Churyukanova, M.; Zhukova, V. Tailoring of magnetic properties of Heusler-type glass-coated microwires by annealing. J. Alloys Compd. 2018, 732, 561-566. [CrossRef]

116. Evstigneeva, S.A.; Nematov, M.G.; Omelyanchik, A.; Yudanov, N.A.; Rodionova, V.V.; Panina, L.V. Hard Magnetic Properties of Co-Rich Microwires Crystallized by Current Annealing. IEEE Magn. Lett. 2020, 11, 1-5. [CrossRef]

(C) 2020 by the authors. Licensee MDPI, Basel, Switzerland. This article is an open access article distributed under the terms and conditions of the Creative Commons Attribution (CC BY) license (http://creativecommons.org/licenses/by/4.0/). 